\title{
La Necrópolis Tardoantigua de la ORDEN-SEMINARIO (HUELVA): RITUALES FUNERARIOS Y ASPECTOS ANTROPOLÓGICOS
}

\author{
CRistóbal Batanero Martín \\ Ánfora GIP \\ José Manuel Beltrán Pinzón \\ Juan Carlos Vera Rodríguez \\ Universidad de Huelva
}

Recibido: 03/02/2016

Revisado: 19/04/2016

Aceptado: $11 / 05 / 2016$

Publicado: 30/06/2016

\section{RESUMEN}

La necrópolis tardoantigua de época visigoda de La Orden-Seminario (Huelva) se encuentra entre los vestigios arqueológicos que han puesto de manifiesto la gran importancia de este yacimiento, y constituye una de las escasísimas evidencias sobre necrópolis rurales de esta clase con que contamos a nivel local y regional. Su hallazgo es de capital relevancia para el mejor conocimiento del ceremonial funerario establecido durante la Antigüedad tardía, un período histórico que hasta la fecha aún no ha sido bien definido y sobre el que existe un cierto vacío teórico.

\section{Palabras Clave}

necrópolis; visigodo; ceremonial funerario; antigüedad tardía.

\section{ABstRact}

Late-Ancient Visigothic Era cemetery of La Orden-Seminario (Huelva) is found between archeological remains that revealed this archeological site great significance. This means this is one of the scarcest evidences of rural necropolis in this class we possess both on local and regional level. This finding is a key point for the best understanding of funerary ceremonies established during Late Antique Age, a historic period that until the date has not been well defined and in which exists a certain theoretical emptiness.

\section{KEYWORDS}

necropolis; visigothic; funerary ceremonies; late antiquity. 


\section{INTRODUCCIÓN.}

Desde el año 2005 se han venido realizando una serie de intervenciones arqueológicas preventivas y de urgencia en el marco de los trabajos de urbanización del denominado Plan Parcial 8 "Seminario" de Huelva, ámbito que ha sido administrativamente integrado, a raíz de los importantes hallazgos e investigaciones arqueológicas llevadas a cabo en dicha extensión, dentro del Sector B3 (Santa MartaLa Orden) de la Zona Arqueológica de la capital onubense. La zona en cuestión, que es conocida por la historiografía reciente como yacimiento de La Orden-Seminario (González et al., 2008, 1; Vera et al., 2010, 202-207), conforma un extenso solar rectangular, actualmente delimitado y protegido, de 23 hectáreas de superficie, que está situado en la periferia norte del casco urbano de Huelva, donde se han localizado más de 3000 estructuras arqueológicas negativas que atestiguan una ocupación continuada desde el Neolítico final hasta época contemporánea.

Por varios motivos, esta actuación ha supuesto una de las intervenciones de mayor calado en la ciudad de Huelva en las últimas décadas, pero sobre todo destaca por la gran cantidad y diversidad de los restos arqueológicos investigados, que abarcan una secuencia milenaria y casi continuada en el tiempo, y por el excelente estado de conservación y calidad de los registros documentados. Los trabajos realizados en el viario y en diversas parcelas de la urbanización fueron promovidos y ejecutados por la empresa Ánfora GIP, con el asesoramiento científico de miembros de la Universidad de Huelva, como son los profesores doctoresJ. C. Vera Rodríguez y F. Gómez Toscano.

La documentación manejada para la elaboración de este estudio procede del conjunto de dichas intervenciones arqueológicas y de los trabajos e informes antropológicos realizados por la investigadora I. López Flores (2006; 2009)1. Por otra parte, el artículo que aquí presentamos es una síntesis del Trabajo Fin de Master de la Universidad de Huelva realizado por uno de los firmantes durante el curso $2012 / 2013^{2}$.

1 Agradecemos a la antropóloga e investigadora Inmaculada López Flores sus numerosas y valiosas aportaciones $\mathrm{y}$ rectificaciones al texto final de este trabajo.

2 Batanero Martín, C. (2013): Las necrópolis tardoantigua e islámicas del yacimiento de La Orden-Seminario de Huelva, Trabajo Fin de Master, Universidad de Huelva.Inédito.
II. SITUACIÓN DE LA NECRÓPOLIS Y DISTRIBUCIÓN ESPACIAL DE LAS ESTRUCTURAS FUNERARIAS.

La necrópolis tardoantigua de La Orden-Seminario está compuesta por nueve estructuras funerarias situadas en la zona noroeste del yacimiento, en el denominado sector "Vial 2B" y agrupadas en su parte central (figura 1). La necrópolis, que ocupa un espacio de alrededor de $282 \mathrm{~m}^{2}$, se ubica en la ladera septentrional de una de las pequeñas elevaciones que conforman el yacimiento y muy próxima al arranque de la vaguada que lo cruza en sentido SO$\mathrm{NE}$, en una zona de suave pendiente con cota en torno a los 41 m.s. n. m.

Algunas de las tumbas presentan relaciones físicas de corte con otras estructuras posteriores, como zanjas, silos o fosas, por lo que en parte han sido alteradas superficialmente, no obstante se encuentran en un estado de conservación óptimo.

El conjunto de estructuras que forman la necrópolis podría dividirse en tres grupos según su distribución: un primer grupo, con una disposición muy regular, estaría compuesto por las tumbas 1259 , 1258 y 1474 , que se encuentran alineadas lateralmente de Norte a Sur respectivamente y con una separación media entre ellas de unos $2 \mathrm{~m}$ aproximadamente. Un segundo grupo estaría comprendido por las estructuras $1475,1257,2238$ a, 2238b y $2238 \mathrm{c}$, que siguen una alineación frontal Oeste-Este respectivamente, formando una hilera a partir de los pies de la tumba 1474, y con una separación entre ellas de unos $3 \mathrm{~m}$ de media, si bien las tres últimas estructuras se encuentran más próximas entre sí con respecto a las demás. Por último, tenemos la estructura 2246, la cual se encuentra aislada al Sur de las anteriores y separada de aquellas por unos 5 $\mathrm{m}$ aproximadamente.

Cabe destacar que la agrupación de enterramientos hispano-visigodos de La Orden-Seminario se localiza en una zona del yacimiento que en fases sucesivas será igualmente utilizada como área cementerial, habiéndose documentado a unos $25 \mathrm{~m}$ más al Norte dos episodios de enterramientos islámicos, el primero correspondiente a un momento emiral-califal (ss. IX-X) y el otro adscrito a la época almohade ${ }^{3}$.

III. LAS ESTRUCTURAS Y SUS CONTEXTOS FUNERARIOS Estructura 1257. Fosa de planta rectangular con los extremos redondeados, paredes rectas y fondo 3 Véase supra nota 2. 


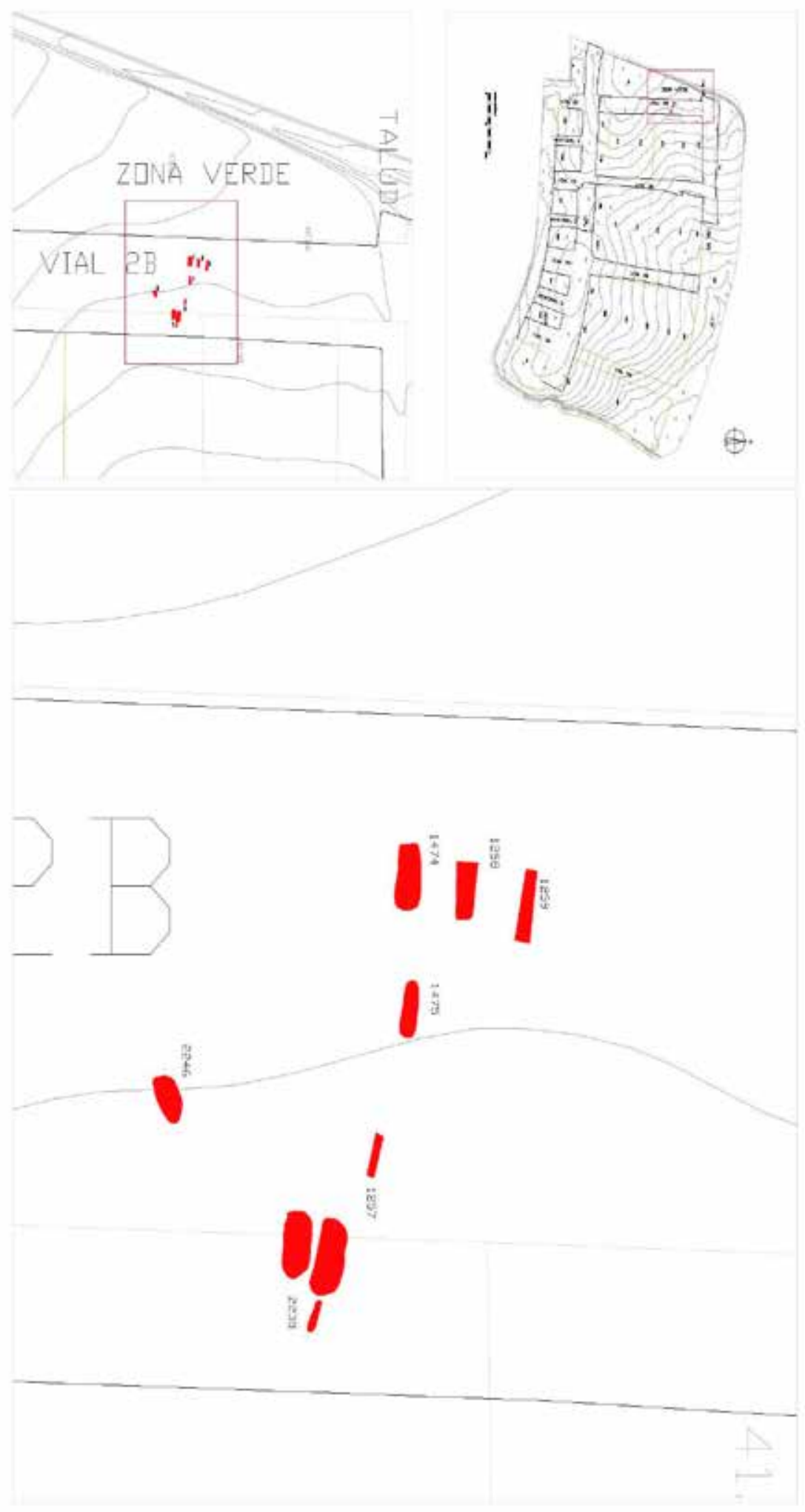

Figura 1. Distribución espacial de las estructuras funerarias. 
plano, con una orientación Este-Oeste. Tiene unas dimensiones de 1,59 $\mathrm{m}$ de longitud, 0,40 $\mathrm{m}$ de anchura y una profundidad de $0,28 \mathrm{~m}$ (figura 2). La estructura aloja un enterramiento primario correspondiente a un individuo infantil de entre 11-12 años, y una estatura de $1,50 \mathrm{~m}$, colocado en posición decúbito supino con brazo derecho extendido e izquierdo flexionado sobre abdomen y piernas extendidas, con una orientación de sagital a $285^{\circ}$ Oeste y cara hacia el Este. No contiene ajuar.

Estructura 1258. Fosa de planta rectangular, paredes verticales y fondo plano, con una orientación Este-Oeste. Tiene unas dimensiones de $2,14 \mathrm{~m}$ de longitud, 0,98 $\mathrm{m}$ de anchura y una profundidad de $0,55 \mathrm{~m}$. El revestimiento de las paredes dota a la estructura de una planta trapezoidal, más ancha en la cabecera que a los pies, y está formado por seis hiladas de ladrillos dispuestos a soga y tizón de manera irregular y aleatoria (figura 3). La cubierta tiene unas dimensiones de 2,18 $\mathrm{m}$ de longitud y $0,88 \mathrm{~m}$ de an- chura, y está formada por lajas de pizarra, fragmentos de ladrillo y un sillar de piedra calcarenita.

Esta estructura funeraria aloja un enterramiento primario que corresponde a un individuo adulto maduro masculino, de unos 50-60 años y una estatura de entre $1,60 \pm 6,96 \mathrm{~m}$, colocado en posición decúbito supino con brazo derecho flexionado sobre abdomen y piernas extendidas, con sagital orientado a $275^{\circ}$ Oeste. El individuo inhumado presenta lesiones articulares degenerativas generalizadas en el esqueleto, dos fracturas resueltas en brazo derecho y hombro izquierdo y una musculatura bastante desarrollada, especialmente la que afecta a las extremidades superiores En contexto secundario encontramos una deposición funeraria colocada a los pies del individuo y que se correspondería con la primera inhumación de la tumba, antes del reaprovechamiento de la misma. Estos restos corresponden a un individuo adulto joven femenino de unos 35-40 años y estatura de entre 1,54 $\pm 5,96 \mathrm{~m}$.,
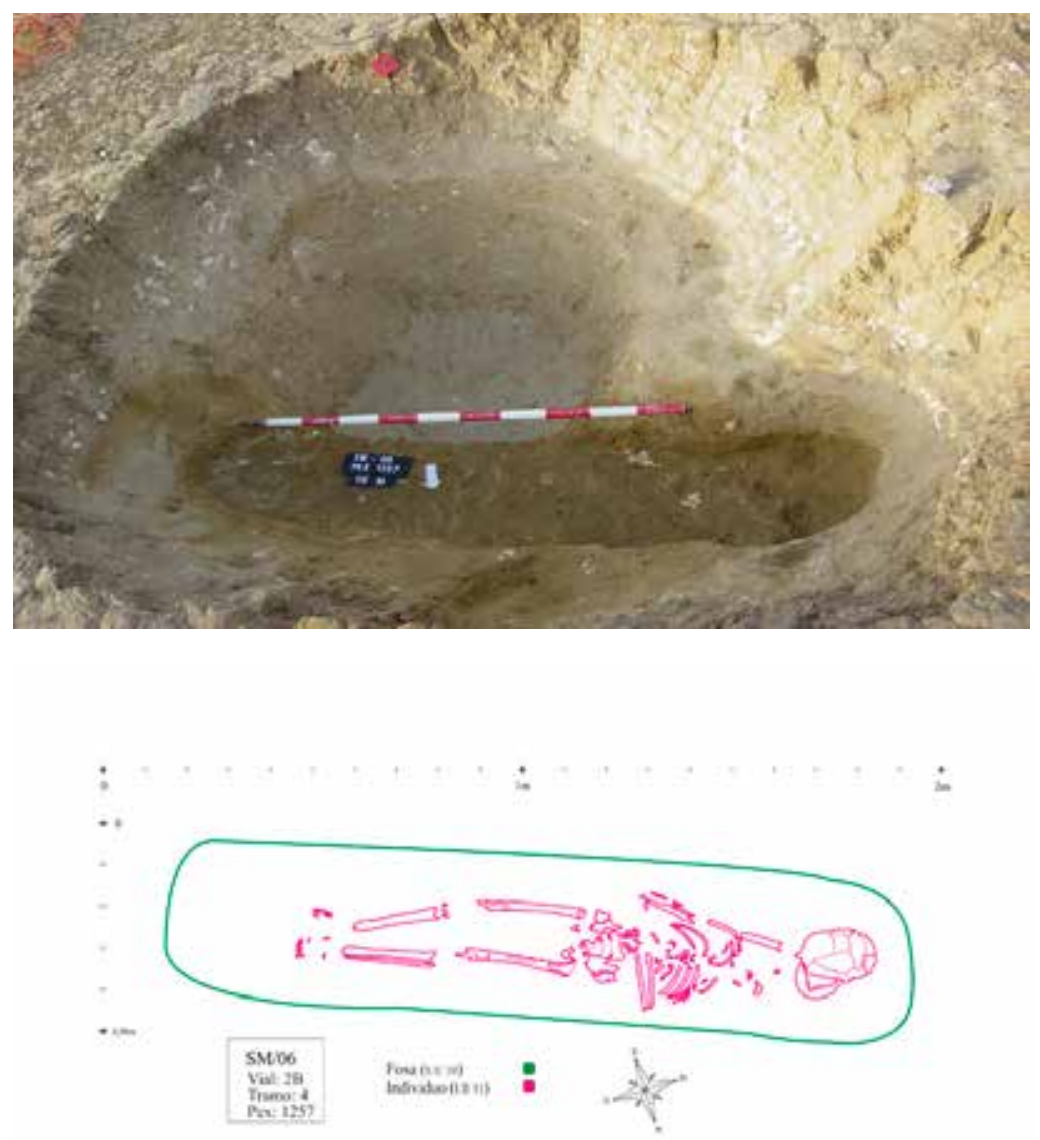

Figura 2. Estructura 1257. Contextos funerarios. 

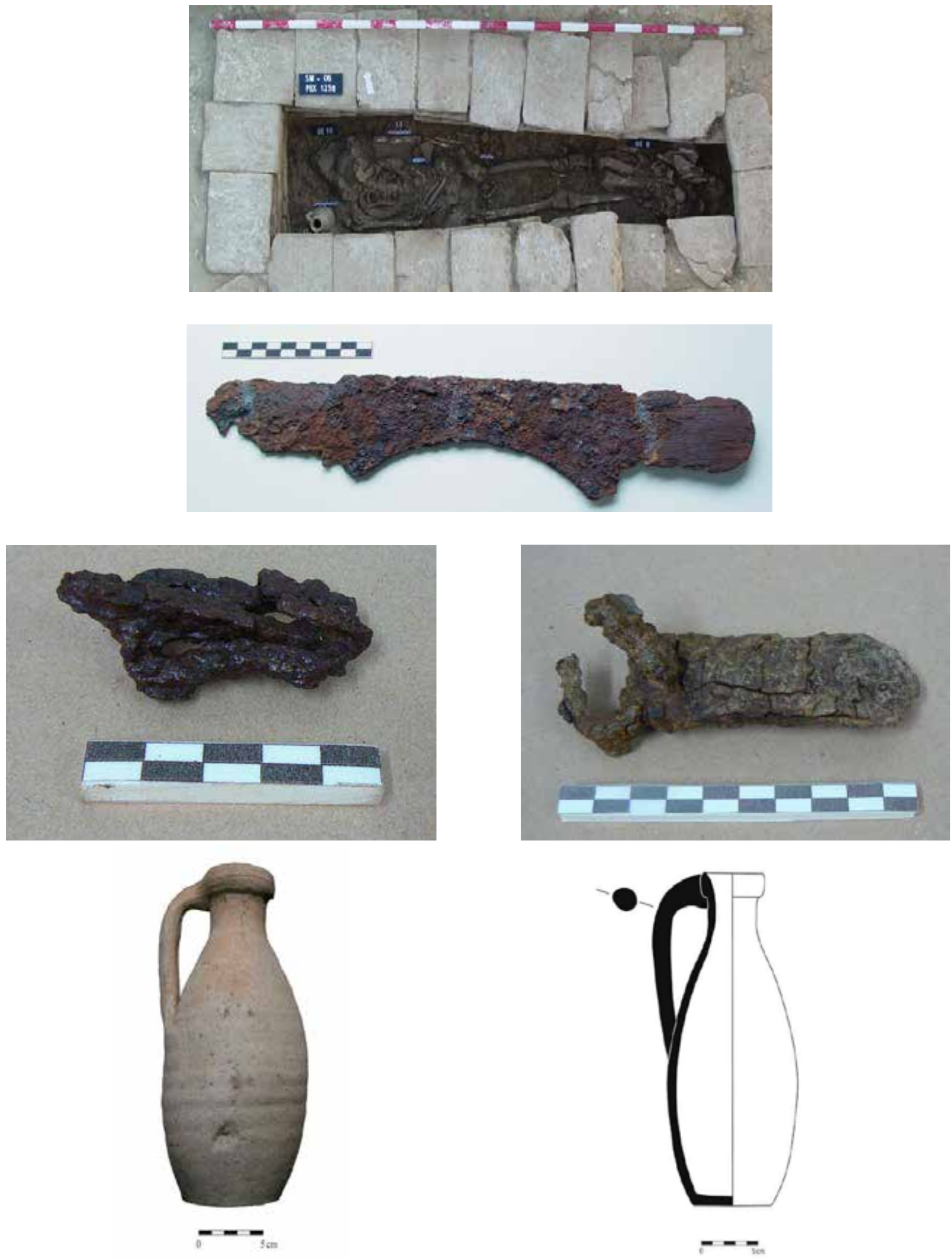

Figura 3. Estructura 1258. Contextos funerarios y elementos de ajuar. 
que comparte con el anterior la presencia de huesos sesamoideos, carácter no métrico de cierto componente genético que permite sugerir posibles vínculos de parentesco.

El ajuar funerario (figura 3) está compuesto por cuatro elementos: una jarrita cerámica, una hoja de hierro perteneciente a una herramienta para el curtido de pieles, una hebilla de hierro de cinturón pequeña y otra de mayor tamaño.

La jarrita es de un solo asa y cuerpo fusiforme, de color beige, con estrecho gollete de sección cilíndrica, boca circular y labio moldurado hacia el exterior, y la base es de fondo plano. Presenta un asa de cinta de sección oval que parte de la boca del recipiente y descansa en la zona central del cuerpo. Tiene una altura de $19 \mathrm{~cm}$ y un diámetro en la base de $6,4 \mathrm{~cm}$. Esta jarrita está colocada a la derecha del cráneo.

La pieza metálica de hierro correspondiente a una herramienta para curtir la piel presenta una hoja plana de filo convexo que se desarrolla a partir de dos apéndices salientes laterales. A ambos lados de la hoja se disponen dos espigones rectos que constituyen los enmangues de la pieza, redondeados en los extremos para insertar sendos mangos de madera. En uno de estos extremos la pieza aún conservaba restos de madera. Tiene una longitud de $30,36 \mathrm{~cm}$ y una anchura de $7 \mathrm{~cm}$. Este elemento se encontró bajo el costado del cuerpo, entre el brazo y la caja torácica.

El broche de cinturón grande de hierro es de placa rígida sencilla y perfil liriforme con apéndice en su zona distal, sin decoración. Se caracteriza por tener la hebilla y la placa fundidas en una sola pieza. La hebilla es de forma arriñonada, está incompleta y le falta también el hebijón. Tiene unas dimensiones de $10,5 \mathrm{~cm}$ de longitud incluyendo placa $\mathrm{y}$ hebilla, una anchura de $2,8 \mathrm{~cm}$ en la zona central de la placa y 4,6 cm en la hebilla. Se encontraba sobre la hoja de curtidor a la altura del codo izquierdo.

El último de los elementos de ajuar está representado por una hebilla de cinturón pequeña de hierro de forma ochavada y sencilla sin decoración. Presenta hebijón o aguja completa y apoyada en la mortaja. Fue hallada junto a la muñeca izquierda.

Estructura 1259. Fosa de planta rectangular con paredes verticales y fondo plano, con una orientación Este-Oeste con la cabecera a $274^{\circ}$ Oeste. Tiene unas dimensiones de 2,50 $\mathrm{m}$ de longitud, 1,04 m de anchura y una potencia de $0,48 \mathrm{~m}$. La cubierta está construida mediante cascotes de ladrillo, conservándose únicamente en la cabecera de la tumba (figura 4). Las paredes de la fosa están revestidas con una caja de ladrillos cuyo aparejo es también irregular, intercalando algunos fragmentos de tegulae y pequeños ripios pétreos a modo de calzo.

Se ha identificado una interfacies de expolio que ha destruido toda la mitad Este de la estructura, habiendo desaparecido casi la totalidad de la depo-

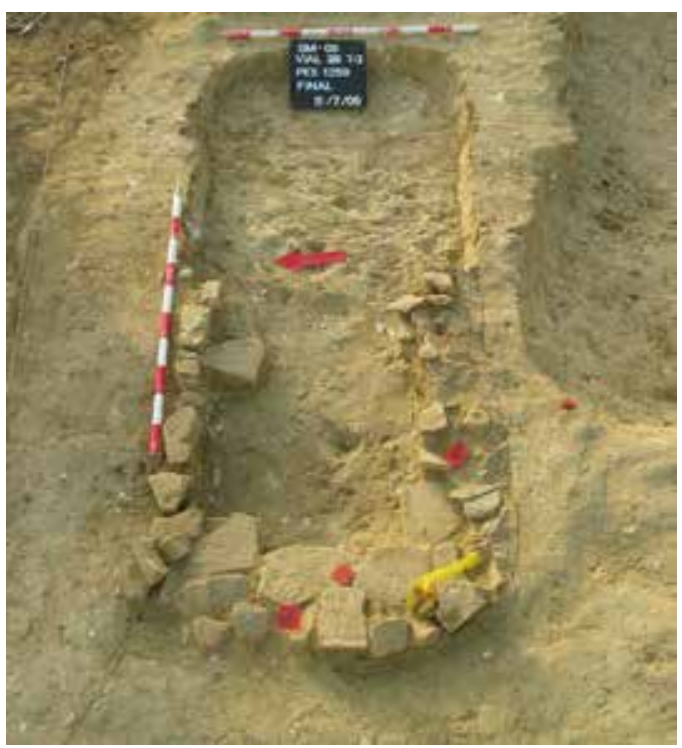

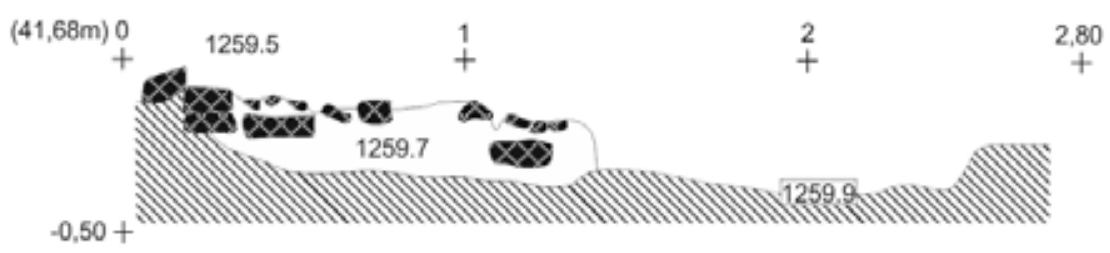

Sección transversal.

Figura 4. Estructura 1259. Contextos funerarios. 
sición funeraria. Únicamente se han hallado algunos restos óseos en posición secundaria en el relleno que colmata la fosa de expolio posterior a la estructura. Los restos corresponden a un adulto masculino, sin que sea posible especificar más debido a lo escaso y al estado de conservación de los mismos. No contiene ajuar.

Estructura 1474. Fosa de planta rectangular con paredes rectas y fondo plano, con una orientación Este-Oeste. Tiene unas dimensiones de 2,28 $\mathrm{m}$ de longitud, 0,86 $\mathrm{m}$ de anchura y una profundidad de $0,62 \mathrm{~m}$. La fosa está revestida con una caja de ladrillos alternando una hilada inferior con los ladrillos dispuestos en vertical y una superior en horizontal a soga. La altura conservada de este revestimiento es de $0,45 \mathrm{~m}$. En ambos laterales de la cabecera se disponen dos grandes lajas de pizarra que completan el revestimiento de la fosa (figura 5). La parte conservada de la cubierta tiene unas dimensiones de 2,03 $\mathrm{m}$ de longitud y $0,80 \mathrm{~m}$ de anchura, y está construi-

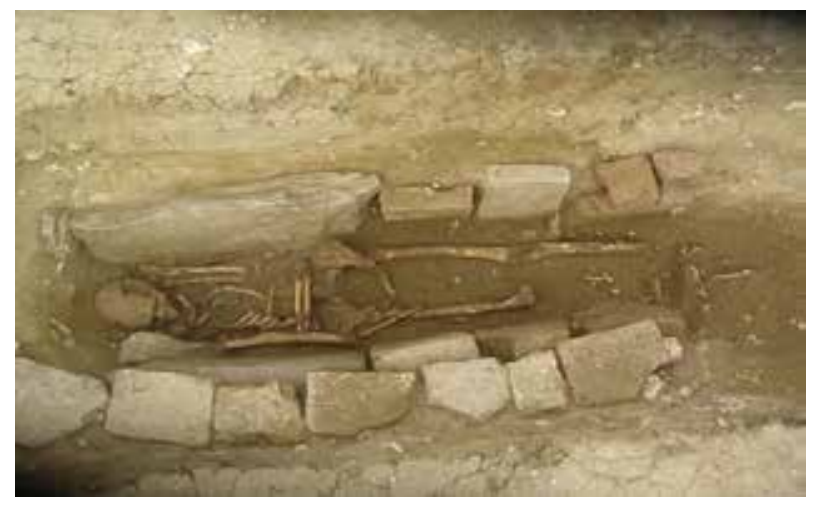

\section{(n)}

da a base de lajas de pizarra, bloques irregulares de calcarenita y fragmentos de ladrillo. En el extremo oriental de la cubierta y aprovechando un hueco en la misma, encontramos una pequeña estructura circular de piedras de 0,65 $\mathrm{m}$ de diámetro que delimita una deposición funeraria en contexto secundario en forma de osario.

La estructura principal aloja un enterramiento primario que contiene los restos de un individuo masculino adulto maduro de entre 40-50 años con una estatura aproximada de 1,64 $\pm 6^{\prime} 96 \mathrm{~m}$ colocado en posición decúbito supino con brazos flexionados sobre el abdomen y piernas extendidas, con una orientación de sagital a $280^{\circ}$ Oeste. El individuo presenta varias lesiones de tipo traumático y osteoarticular.

El osario corresponde a los restos de un individuo adulto joven masculino de entre 33-42 años y se encuentra prácticamente la totalidad del esqueleto.

$\mathrm{El}$ ajuar corresponde al enterramiento primario
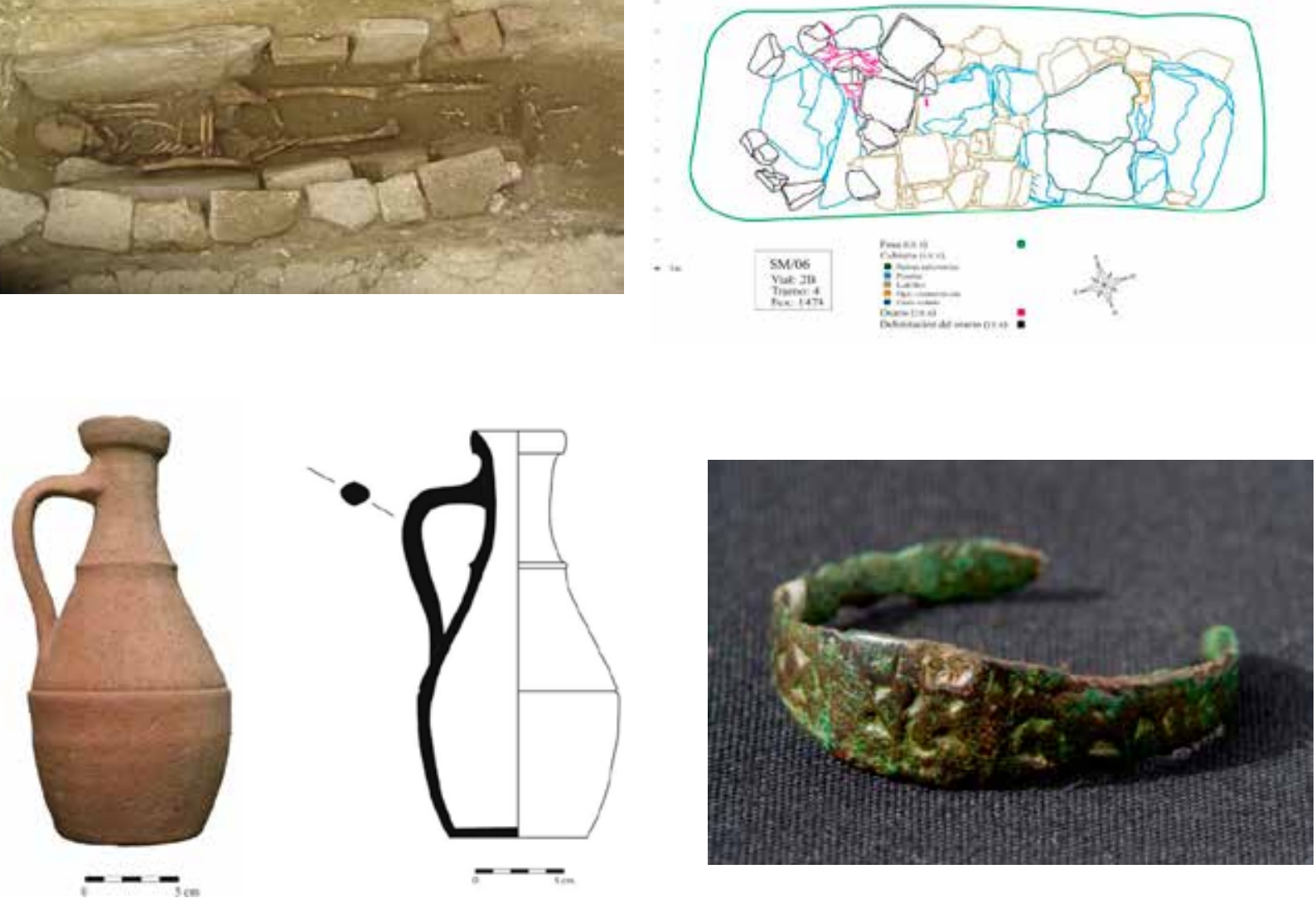

Figura 5. Estructura 1474. Contextos funerarios y elementos de ajuar. 
y está representado por un único elemento, una jarrita de cerámica de un solo asa, de cuerpo bitroncocónico y color ocre anaranjado, más estrecha en el cuello que en la base. Presenta un tosco alisado en su superficie. El cuello es corto y cilíndrico, con una boca circular de borde moldurado asimétrico. El asa es de sección oval, partiendo del cuello para apoyar sobre la zona media de la parte superior de la vasija, y la base es de fondo plano. Tiene una altura de 19,5 $\mathrm{cm}$ y un diámetro en la base de $6,9 \mathrm{~cm}$ (figura 5 ). Esta jarrita está colocada a la derecha del cráneo.

Asociado al osario se ha hallado una pieza metálica, correspondiente a un anillo de bronce con el frente ensanchado y marcado con dos incisiones a cada lado del chatón. Tiene decoración repujada cuyos motivos geométricos consisten en dos peltas afrontadas por sus ápices en el centro del chatón, flanqueadas por dos pares de triángulos enfrentados por sus vértices verticalmente. A partir del chatón y a ambos lados del mismo presenta series de dos triángulos enfrentados por sus vértices en vertical alternando seguidamente con otros dos en horizontal (figura 5).

Estructura 1475. Fosa de planta rectangular con paredes verticales y fondo plano, con una orientación Este-Oeste y dimensiones de $1,87 \mathrm{~m}$ de longitud, 0,47 $\mathrm{m}$ de anchura y una profundidad de $0,27 \mathrm{~m}$. No presenta cubierta ni revestimiento en las paredes (figura 6). Esta estructura contiene una inhumación primaria cuyo individuo está colocado en posición decúbito supino con brazo izquierdo extendido, derecho semiflexionado sobre abdomen, piernas extendidas, y con sagital orientado a $280^{\circ}$ Oeste. Los restos se encuentran en mal estado de conservación y parte del esqueleto ha desaparecido. No obstante el estudio antropológico revela que se trata de un individuo masculino adulto con una estatura de 1,61 $\pm 8^{\prime} 44 \mathrm{~m}$. No contiene ajuar.

Estructura 2238a: Fosa de planta rectangular con los extremos redondeados, paredes rectas y fondo plano. Su orientación es Este-Oeste. Tiene unas dimensiones de 2,72 $\mathrm{m}$ de longitud, una anchura de $1,10 \mathrm{~m}$ y una profundidad de $0,44 \mathrm{~m}$. Está revestida con una caja de ladrillos compuesta por dos hiladas de ladrillos a soga cuyo módulo es de $29 \times 23 \times 7 \mathrm{~cm}$ (figura 7). La cubierta de la tumba está construida mediante sillares, lajas de pizarra, fragmentos de tegulae y ladrillos.

En el extremo Oeste de la tumba encontramos una pequeña estructura semicircular que corta a la cabecera, separada de ésta por una hilada de ladrillos, dándole al conjunto en esta parte el aspecto de una cabecera ampliada y más redondeada. Esta estructura semicircular tiene unas dimensiones de $0,45 \mathrm{~m}$ de longitud y $0,65 \mathrm{~m}$ de anchura. Su cubierta está formada por lajas de pizarra de mediano tamaño y fragmentos de ladrillo (figura 7).

La tumba presenta un enterramiento primario que contiene los restos de un individuo masculino adulto maduro de 55-70 años con una estatura de $1,64 \pm 6^{\prime} 96 \mathrm{~m}$, colocado en posición decúbito supino con brazos flexionados sobre abdomen y piernas

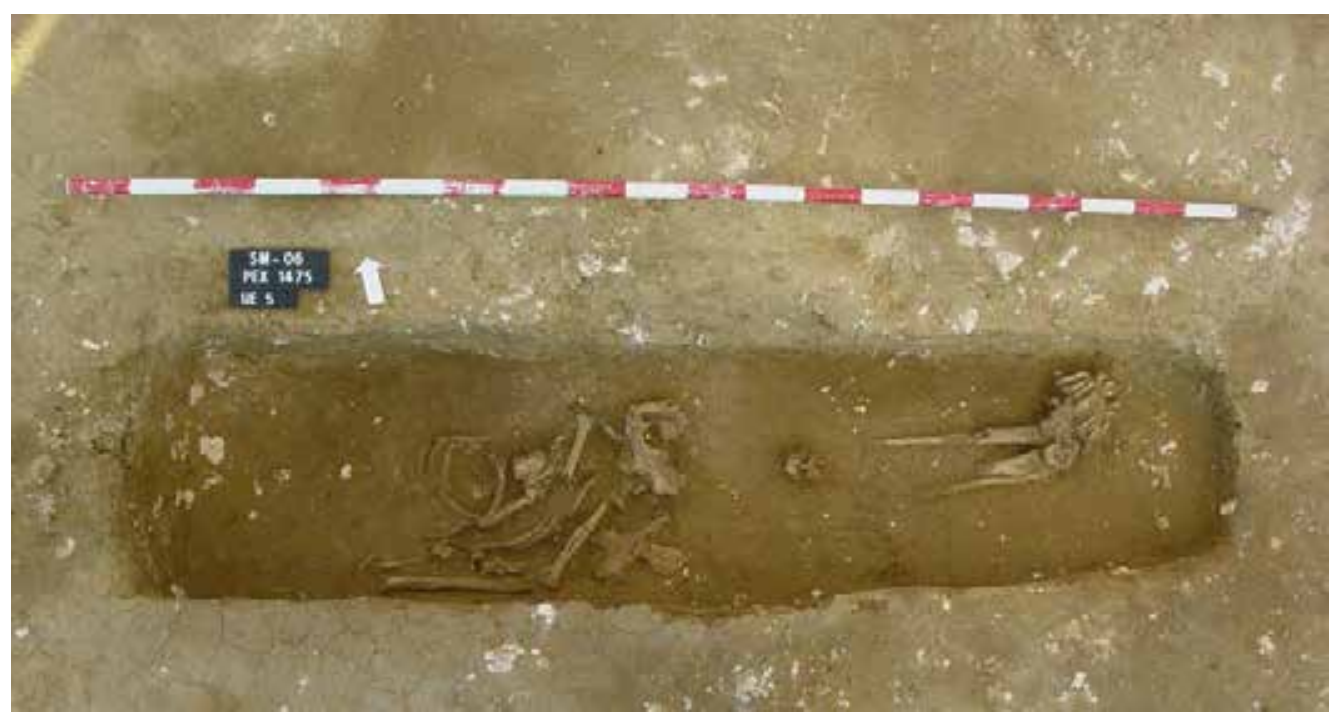

Figura 6. Estructura 1475. Contexto funerario. 
extendidas, con sagital orientado a $285^{\circ}$ Oeste. Se detecta en el cadáver abundante patología osteoarticular, metabólica y odontológica.

La estructura semicircular localizada en la cabecera de esta tumba aloja restos en posición secundaria, que probablemente se corresponda con el primer enterramiento de este conjunto y que fue desalojado de la tumba para depositar al nuevo individuo. Se trata de los restos no articulados de un individuo masculino adulto maduro con una estatura de 1,61 $\pm 6^{\prime} 96 \mathrm{~m}$., también con diversas patologías, principalmente osteoarticular.

El ajuar funerario del enterramiento primario está formado por un elemento: una jarrita cerámica de cuerpo piriforme asimétrico, con cuello alargado y cilíndrico, de color ocre anaranjado, ligeramente ensanchado en su zona media, de la que arrancan dos asas simétricas de sección oval que llegan hasta la mitad de la panza. Presenta un borde de tipo moldurado y una base de fondo convexo. Tiene una altura de 20,4 cm y un diámetro en la base de 7,3 $\mathrm{cm}$ (figura 7). Esta pieza se encuentra situada sobre el fémur izquierdo, en una posición diferente a las localizadas en otras tumbas ya descritas donde se localiza a la derecha del cráneo.

Estructura 2238b: Se localiza apenas $1 \mathrm{~m}$ hacia el Este de la anterior. Fosa de planta rectangular con los extremos redondeados, paredes rectas y fondo plano, con una orientación Este-Oeste. Tiene unas dimensiones de $1,54 \mathrm{~m}$ de longitud, una anchura de $0,40 \mathrm{~m}$ y una profundidad de $0,27 \mathrm{~m}$ (figura 8). La cubierta está formada por lajas de pizarra y fragmentos de ladrillo, y la parte conservada tiene unas dimensiones de $0,90 \mathrm{~m}$ de longitud y $0,46 \mathrm{~m}$ de anchura.

Esta estructura funeraria aloja un enterramiento primario que contiene los restos de un individuo infantil de 7-8 años y con una estatura de 1,41 m.
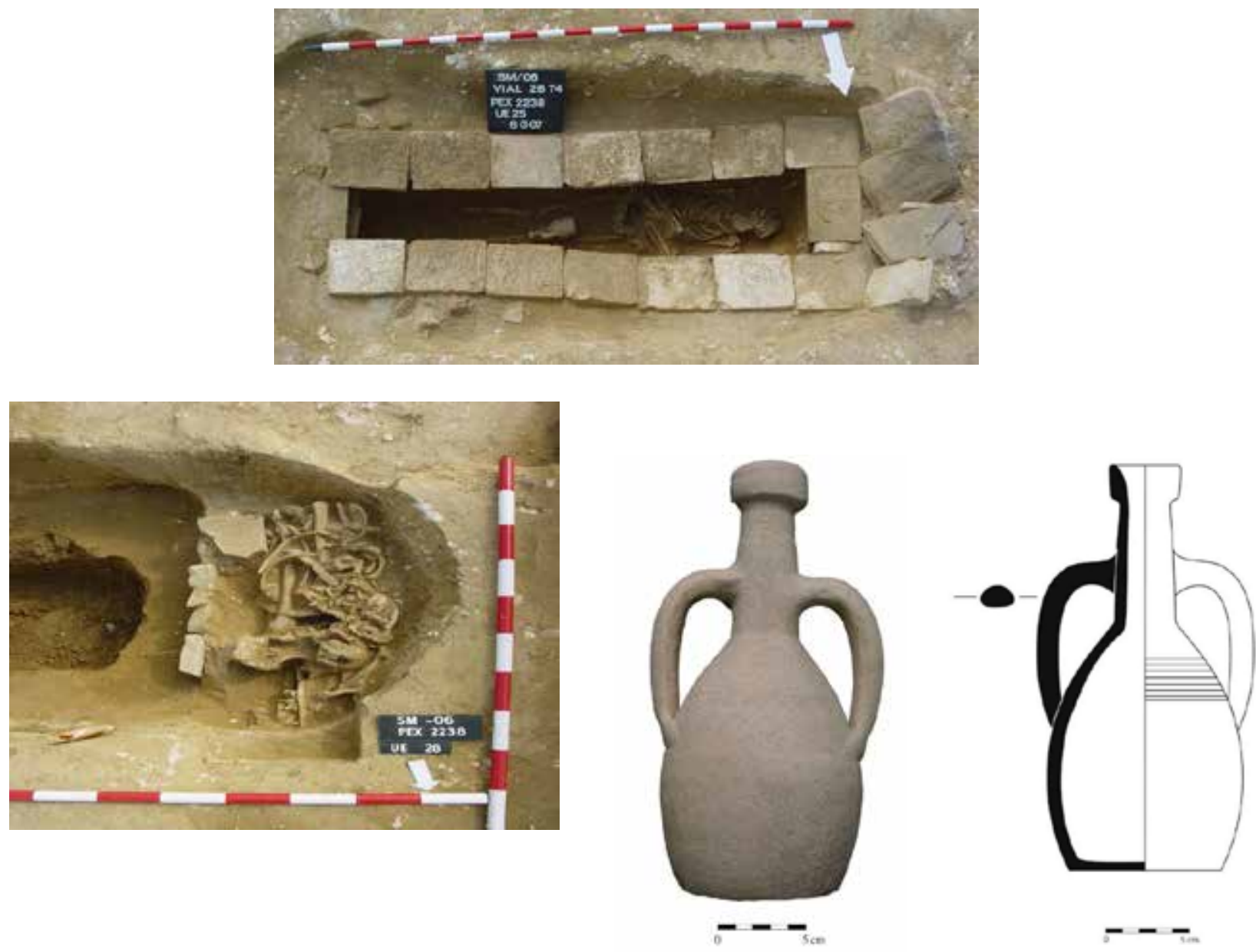

Figura 7. Estructura 2238a. Contextos funerarios y elemento de ajuar. 

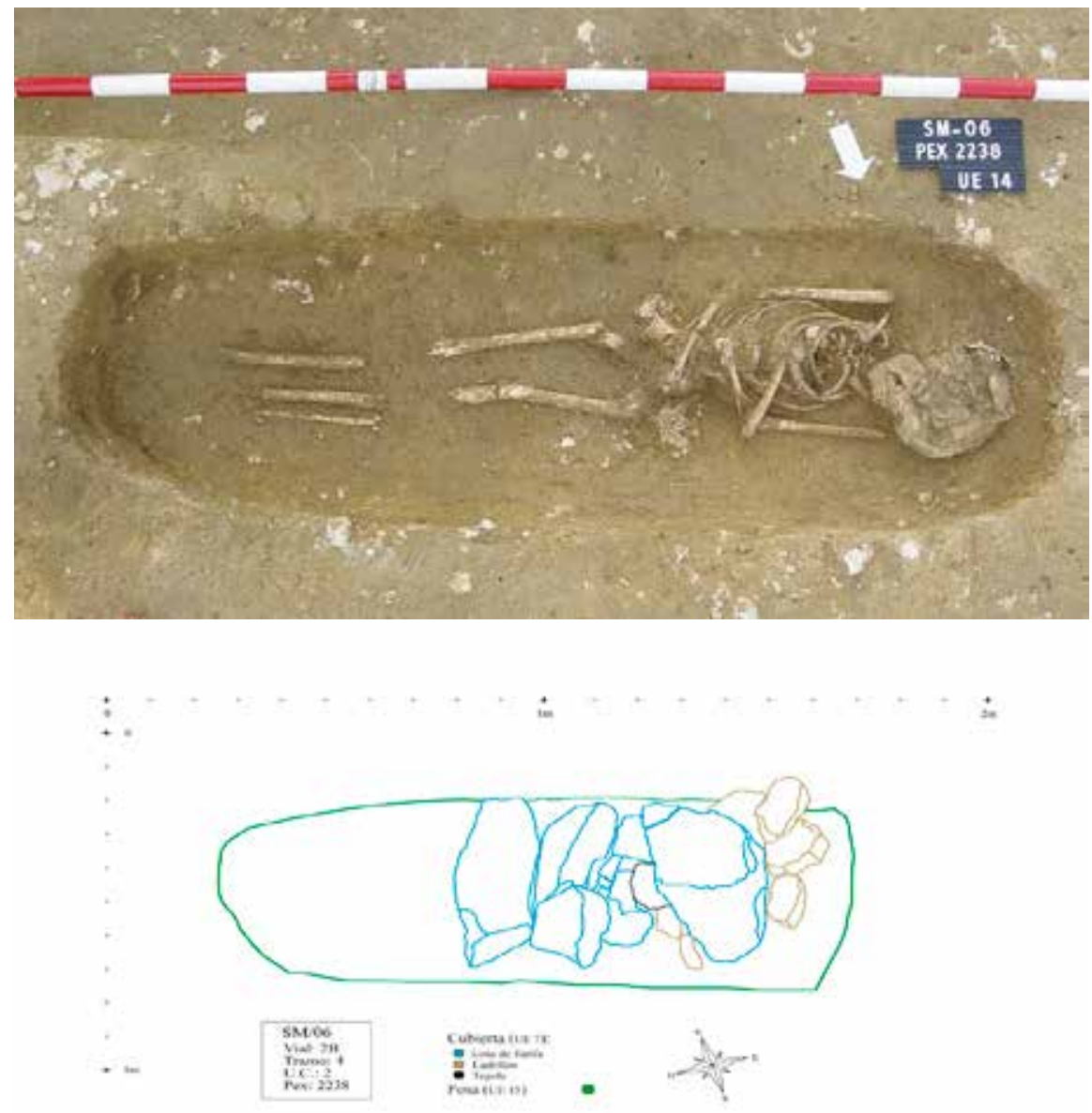

Figura 8. Estructura 2238b. Contextos funerarios.

Está colocado en posición decúbito supino con brazos flexionados sobre abdomen y piernas extendidas, con sagital orientado a $300^{\circ}$ Oeste y cara hacia el Noreste. Se detecta el posible uso de un sudario. No contiene ajuar.

Estructura 2246. Fosa de planta rectangular con los extremos redondeados, paredes verticales y fondo plano, con una orientación Este-Oeste. Tiene unas dimensiones de 1,74 $\mathrm{m}$ de longitud, una anchura de 0,85 $\mathrm{m}$ y una profundidad de $0,65 \mathrm{~m}$ (figura 9). La estructura presenta una cubierta compuesta por dos grandes lajas de piedra y fragmentos de ladrillo. La fosa de inhumación aloja un enterramiento primario correspondiente a un individuo infantil de entre 7-8 años y estatura de 1,22 m aproximadamente. Está colocado en posición decúbito supino con brazos y piernas extendidas, y con una orientación sagital a $240^{\circ}$ Suroeste. El estudio antropológico revela el posible uso de un sudario o mortaja. No contiene ajuar.
Estructura 2238c: Se localiza apenas a $1 \mathrm{~m}$ al Sur de 2238a. Fosa de planta rectangular, paredes rectas y fondo plano, con una orientación Este-Oeste. Tiene unas dimensiones de 2,38 $\mathrm{m}$ de longitud, 0,98 $\mathrm{m}$ de anchura y una profundidad de $0,39 \mathrm{~m}$. La fosa está revestida con una caja de ladrillos cuya longitud máxima es de $2,03 \mathrm{~m}$, siendo más ancha en la cabecera, donde tiene una anchura de 0,87 m. Este revestimiento está formado por tres hiladas de ladrillos a soga cuyo módulo es variable (figura 10). La cubierta de la tumba está construida mediante fragmentos de ladrillos y tegulae, pizarras, y dos sillares de roca calcárea, uno de ellos en la cabecera y otro a los pies. Presenta unas dimensiones de $2 \mathrm{~m}$ de longitud y 1,04 $\mathrm{m}$ de anchura.

Esta estructura aloja restos en posición secundaria en la zona central del interior de la tumba. Estos restos corresponden a un individuo neonato y dos infantiles de entre 3 y 4 años. 


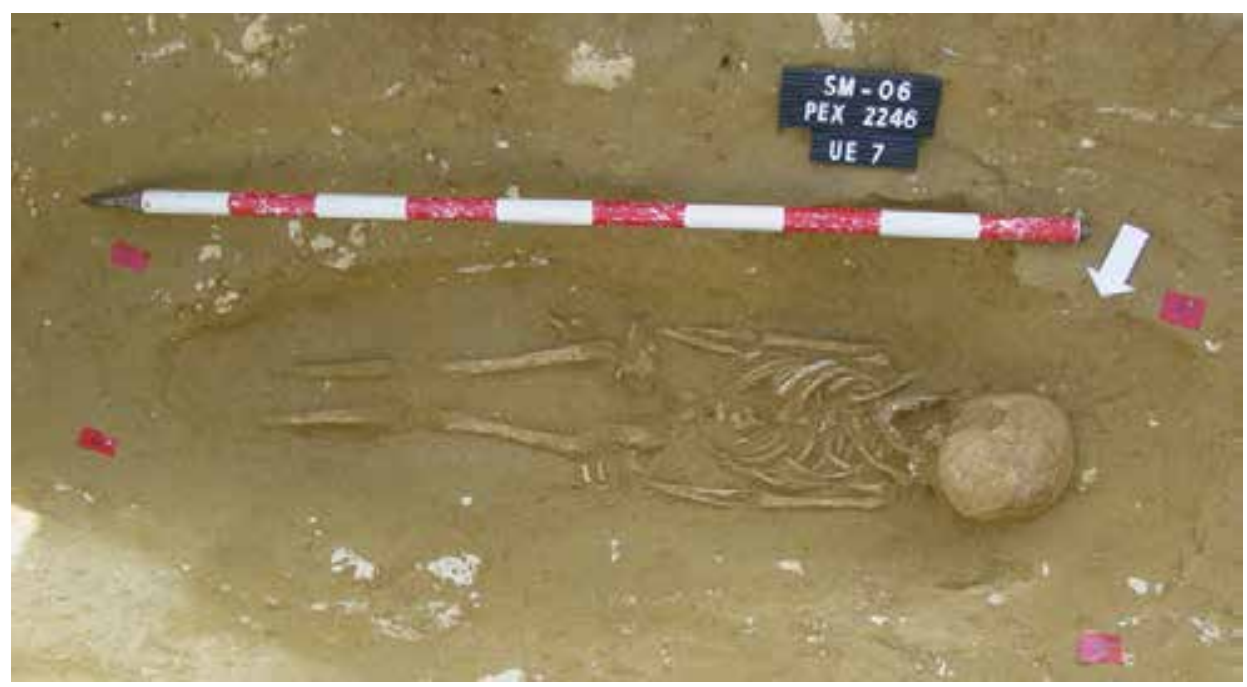

Figura 9. Estructura 2246. Contexto funerario.
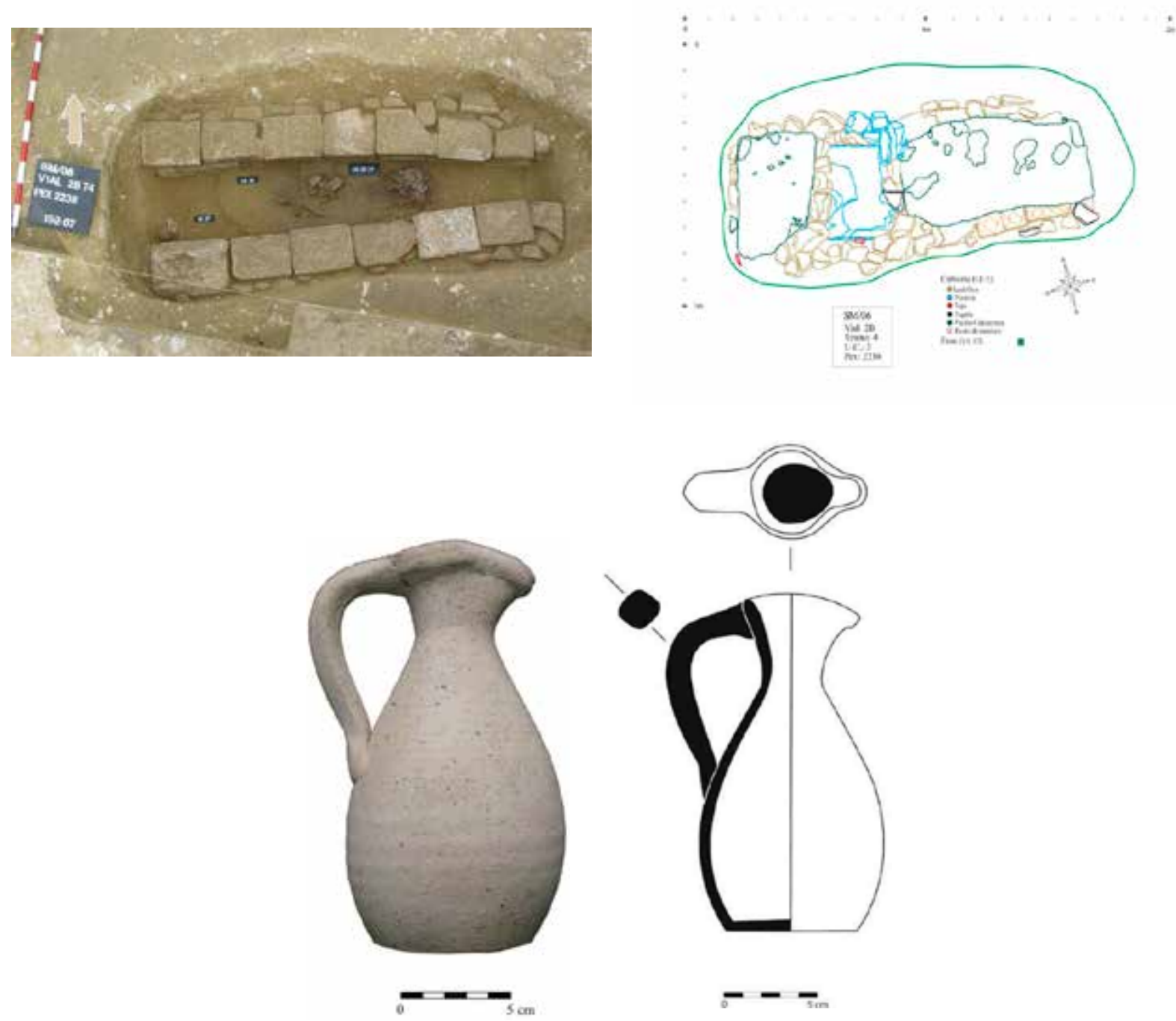

Figura 10. Estructura 2238c. Contextos funerarios y elemento de ajuar. 
El ajuar funerario está compuesto por un solo elemento: una jarrita cerámica similar a las anteriormente descritas, de cuerpo piriforme asimétrico, de color beige blanquecino sin decoración, con estrecho gollete de sección troncocónica invertida que remata en una boca trilobulada de labio moldurado. Presenta un asa de cinta de sección ovalada que arranca del borde y descansa en la zona media del cuerpo, y la base es de fondo convexo. Tiene una altura de $15 \mathrm{~cm}$ y un diámetro en la base de $6 \mathrm{~cm}$ (figura 10). La pieza se localiza en el ángulo suroeste de la cabecera de la tumba y posiblemente esté relacionada con un contexto funerario anterior al osario.

IV. ESTUdio DE LOS CONTEXTOS MATERIALES Y ANTROPOLÓGICOS

\section{IV.1. LAS ESTRUCTURAS FUNERARIAS}

Las tumbas que integran la necrópolis hispanovisigoda de La Orden-Seminario consisten en estructuras negativas excavadas en el sustrato terciario que forma la base geológica del yacimiento. Las fosas presentan, por lo general, planta rectangular o subrectangular, con los extremos ligeramente redondeados, paredes verticales y fondo plano.

En cuanto a sus características morfológicas, existe una clara diferencia entre las estructuras funerarias que presentan revestimiento de las paredes y las que son de fosa simple. Entre las primeras se incluyen las estructuras 1474, 1258, 1259, 2238a, y 2238c, las cuales disponen de paramentos de ladrillos con módulos en torno a $28 \times 21 \times 7 \mathrm{~cm}$ y que configuran plantas interiores rectangulares o trapezoidales. Dentro de este conjunto de tumbas se distingue la estructura 1474 por incorporar a ambos lados de la cabecera sendas lajas de pizarra hincadas verticalmente, un elemento constructivo que encuentra paralelos significativos en enterramientos de la necrópolis de Reynilla (Guadalcázar, Córdoba) (Lacort y Del Pino, 1995: 59). El segundo tipo, formado por las estructuras 1475, 2246, 1257, y 2238 b, consiste en inhumaciones en fosa simple; las tres últimas aparecen asociadas a enterramientos infantiles.

Respecto a las dimensiones de las estructuras hay que indicar que las que ostentan caja de obra ofrecen longitudes que superan los $2 \mathrm{~m}$ y anchuras de alrededor de $1 \mathrm{~m}$, mientras que las de tipo simple exhiben medidas más modestas, no superando en ningún caso el medio metro de anchura. Esta última circunstancia puede deberse quizás, no solo a la propia configuración morfológica de la tumba, sino al hecho de que tres de las documentadas reciben inhumaciones infantiles como hemos indicado.

Invariablemente, las sepulturas se colocan en dirección Este-Oeste, con la cabecera a Poniente y con una orientación predominante que oscila entre $\operatorname{los} 275^{\circ}$ y los $285^{\circ}$ Oeste. Cercano a este rango se sitúa el enterramiento $2238 \mathrm{~b}$, con la cabecera a $300^{\circ}$ Oeste; algo más alejada de la orientación principal se encuentra la tumba 2246, que como se ha mencionado con anterioridad aparece separada del resto y presenta una orientación de $240^{\circ}$ Oeste. Según algunos autores (Morín y Barroso, 2005, 200), estas pequeñas desviaciones de la orientación general son consecuencia de la diferente época del año en la que se construye la sepultura.

Cuatro de las estructuras excavadas muestran claros indicios de haber sido reaprovechadas, toda vez que alojan o aparecen asociadas a enterramientos o a acumulaciones osteológicas en contexto secundario $(1474,1258,2238$ a, y 2238c), dos de ellas de forma inusual dado que se relacionan con deposiciones funerarias realizadas al exterior de la estructura original. Concretamente, la tumba 1474 presenta un osario en el interior de una pequeña estructura circular de piedras, instalada sobre su cubierta aprovechando una pequeña oquedad en ésta, y la 2238a aparece relacionada directamente con un rebaje semicircular adyacente a la cabecera de la tumba, separada de ésta mediante un murete a base de ripio y con cubierta propia de pizarra y ladrillo, que encierra igualmente restos secundarios en forma de osario. Este tipo de deposiciones secundarias en el exterior de las tumbas se han identificado en enterramientos de la necrópolis de la basílica de Gerena, donde a veces los huesos retirados de inhumaciones anteriores se amontonan cerca de la cubierta o sobre ella (Fernández, Sierra y Laso, 1987, 190). Existen también paralelos de esta práctica en la necrópolis de El Ruedo (Carmona, 1998, 174), en la de Las Delicias de Ventas de Zafarraya (Granada) (Toro y Ramos, 1987, 145) y en el extenso cementerio de Cacera de las Ranas (Madrid) (López, 2010, 202).

Por otro lado, las estructuras 1259 y 1474 presentan huellas evidentes de expoliación en forma de fosas o rebajes posteriores que desarticulan los elementos constructivos y las inhumaciones de las mismas. En el caso de la tumba 1259, prácticamente la mitad Este de la estructura ha sido destruida y sólo quedan algunos restos aislados y esparcidos del individuo. En la tumba 1474 ha desaparecido el 
muro de revestimiento a los pies del inhumado y los restos de las extremidades inferiores están alterados e inconexos.

En todas las estructuras, excepto en la 1475 y la 1257 , se han documentado las cubiertas horizontales que cerraban el espacio funerario, las cuales están construidas a base de lajas de pizarra, bloques de piedra calcarenita y ladrillos. En ocasiones sólo se utilizan lajas de pizarra y ladrillos y en otras se añaden también fragmentos de tegulae. Respecto a las dos mencionadas, existen indicios para pensar que también tuvieron cubierta originariamente, ya que el medio de descomposición del inhumado en ambos casos es de tipo aerobio. En lo que se refiere a la tumba 1257 la cubierta pudo ser destruida por una fosa islámica que la corta en todo su perímetro; más difícil es interpretar la ausencia de cubierta en la estructura 1475 , por ser un caso excepcional en la necrópolis, si bien la única explicación plausible es que los materiales que la componían fueran objeto de una reutilización puntual.

\section{IV.2. LAS INHUMACIONES}

De las nueve estructuras registradas, siete de ellas han proporcionado contextos primarios de enterramiento de un número equivalente de individuos (1474, 1475, 1258, 2246, 1257, 2238a, y 2238b), una estructura únicamente contiene restos aislados y descontextualizados (1259), y otra alberga sólo restos en posición secundaria de tipo osario (2238c). Algunas de las sepulturas con inhumaciones primarias anteriormente citadas han aportado además deposiciones de osarios, cada uno de los cuales se corresponde con los restos de un único individuo (1258, 1474 y 2238a). El número mínimo de individuos es de 13 , procedentes tanto de las inhumaciones primarias como de las secundarias.

Al igual que en el resto de las necrópolis tardorromanas y de época visigoda documentadas hasta la fecha, el ritual funerario atestiguado en La Orden-Seminario es la inhumación del cadáver. El rito de la inhumación se extiende de forma generalizada y definitiva por el Imperio Romano a partir del siglo III como consecuencia de la influencia creciente del Cristianismo y de su creencia en la reencarnación de la carne. Este ritual de inhumación es heredero de las prácticas funerarias de inhumación romanas, y consta de varios pasos: lavado y amortajamiento, cortejo fúnebre para el traslado del difunto, sepultura y, por último, banquete funerario que, según las fuentes textuales, se celebraba al noveno día como cierre de los funerales (Carmona, 1998, 100-101).

Los individuos se encuentran en posición decúbito supino con piernas extendidas, siendo variada la posición de las extremidades superiores: éstas pueden disponerse extendidas a lo largo del cuerpo, flexionados los dos brazos sobre el abdomen, o sólo uno de ellos indistintamente. Los cuerpos están orientados Este-Oeste con la cabeza hacia el Oeste, respondiendo al ritual funerario propio de estos contextos y para el que encontramos paralelos en varias necrópolis similares como la de El Ruedo en Almedinilla (Carmona, 1998, 138), la de la Dehesa de la Casa en Cuenca (López y Barroso, 1994, 14) y la de Las Reliquias en Cartaya (López et al., 2009, 1698), entre otras. En las inhumaciones donde se ha podido documentar con precisión, la cara del cadáver aparece dirigida hacia el Este o Noreste.

La posición de las extremidades superiores en las inhumaciones es un tema que ha sido objeto de numerosas hipótesis, pudiendo tener un significado asociado a prácticas funerarias de diverso tipo. Según algunos autores los brazos extendidos a lo largo del cuerpo podría estar vinculado a prácticas paganas, mientras que los brazos flexionados sobre el pecho, interpretado como actitud de oración, se relacionaría con el Cristianismo (Young, 1977, 27). Otros autores aseguran que la modificación encontrada en la disposición de los cadáveres y en concreto de los brazos no refleja de ningún modo la adscripción étnica o cultural del individuo y más bien se trataría de hechos casuales o circunstanciales (Cerrillo, 1989, 99-101).

No obstante, en el caso de la necrópolis tardoantigua de La Orden-Seminario hay que señalar que, aunque entre los individuos exhumados encontramos una representación variada en cuanto a la posición de los brazos, éstos se encuentran flexionados sobre el abdomen y no sobre el pecho, por tanto no cabe interpretación similar sobre este aspecto.

En lo que se refiere a otro de los rasgos del ritual funerario de esta época, como es el amortajamiento del cadáver, el estudio antropológico ha evidenciado el uso probable de sudario en dos de los individuos infantiles (2246 y 2238b).

De las siete estructuras que contienen enterramientos primarios se atestigua el reaprovechamiento del espacio mortuorio en tres de ellas, habiéndose encontrado en su interior, o asociados a éstas, amontonamientos de huesos pertenecientes a otras inhumaciones $(1474,1258$ y 2238a). Estos restos 
corresponden a tres individuos, de los que dos son adultos entre 33-40 años y uno maduro. Dos de ellos son masculinos (1474 y 2238a) y uno femenino (1258). En esta última tumba, los huesos de la primera inhumación fueron retirados y desplazados a los pies de la fosa para alojar el cuerpo de la inhumación final. No podemos asegurar que esta práctica se reprodujera en el caso de las estructuras 1474 y 2238a, ya que los osarios de estas sepulturas no se encuentran depositados en el interior del espacio funerario principal, sino que se alojan en lugares que a posteriori fueron preparados específicamente para su contención, si bien el hecho de que estén vinculadas físicamente a estas tumbas hace suponer que ese proceso se produjo en el espacio principal en algún momento anterior.

En cuanto a la sepultura 2238c, ésta recibe en su zona central los osarios correspondientes a los restos de un individuo neonato y dos infantiles sobre los que no se ha podido obtener más datos debido a su mal estado de conservación. Se da la circunstancia de que en esta tumba se ha hallado in situ la jarrita que constituía, posiblemente, el ajuar funerario de una inhumación primaria anterior que habría sido retirada para disponer los restos de los individuos infantiles. Admitiendo esta lectura y dado que la jarrita se encuentra posicionada en el lado derecho de la cabecera de la tumba y que, como veremos más adelante, con toda probabilidad se relacionaría con un individuo masculino, cabría la posibilidad de que el paquete óseo contenido en la estructura complementaria de la tumba adyacente 2238a, que contiene los huesos conservados de un individuo masculino adulto, y de la que aquélla dista apenas medio metro, fuera el resultado del traslado y la reubicación del cadáver que ocuparía originalmente la tumba 2238c, quedando patente así una supuesta relación familiar entre todos los individuos enterrados en ambos sepulcros.

Finalmente, la estructura 1259 presenta restos aislados de un individuo masculino de edad no determinada, que se hallan esparcidos por el relleno de la fosa de expolio que ha provocado su casi total destrucción.

Además de las evidencias principales, se han localizado restos óseos humanos en los rellenos que colmatan algunas de las fosas funerarias, pero se trata de elementos esporádicos que apenas aportan información relevante.

De las siete inhumaciones primarias, cuatro de ellas corresponden a individuos maduros, con eda- des comprendidas entre 40-50, 50-60 y 55-70 años, y uno de edad no determinada. Tres son infantiles, de los que dos de ellos tendrían entre 7-8 años y uno entre 11-12 años. Los adultos corresponden a individuos masculinos y los infantiles han sido clasificados como alofisos.

Si bien hay casos en los que no se ha podido determinar el sexo de los individuos, podemos decir que predomina la representación de los individuos de sexo masculino $(6$ masculinos frente a 1 femenino). En cuanto a las franjas de edad, existe una importante representación de individuos maduros de más de 40 años e infantiles de menos de 12 años, y una menor representación de individuos jóvenes de menos de 40 años. La edad de muerte de los adultos es moderadamente elevada, encontrándose muchos de ellos en la etapa madura. Se constata también una elevada mortalidad infantil, ya que de las 13 muestras analizadas, seis corresponden a individuos en edad infantil.

Los indicadores de estatura en la población analizada arrojan valores medios de 1,62 $\mathrm{m}$ para los individuos adultos masculinos, y 1,54 m para los femeninos, de los que contamos con un solo registro. Se trataría por tanto de individuos de talla media, sin que se observen de forma destacable grandes diferencias entre ellos.

En general, el estado de conservación de los restos óseos es bueno, salvo alguna excepción, por lo que ha sido posible determinar rasgos funcionales $y$ patologías diversas.

Sobre este particular hay que decir que se han documentado siete individuos con afecciones odontológicas, seis con alteraciones osteoarticulares, cuatro con lesiones traumáticas, tres con patología infecciosa, y otros dos con patología metabólica. El predominio de las patologías osteoarticulares y odontológicas es un rasgo característico entre los individuos que aportan más datos y son, para este periodo, habitualmente frecuentes en individuos adultos. Todas ellas están relacionadas con la dieta alimenticia, la higiene dental, las cargas de trabajo y la edad de los individuos.

En el caso del individuo inhumado en la tumba 1258, se han registrado diversas anomalías de morfología adquirida o funcional, manifiestas en patologías degenerativas en brazos y hombros, lo que, unido al hallazgo de la herramienta para el curtido de pieles que formaba parte de su ajuar funerario, nos lleva a sospechar que dichas alteraciones se deben a la realización de trabajos físicos continuados 
derivados de la actividad profesional u ocupacional a la que se dedicaría el difunto.

Debido a lo escaso de la muestra, los resultados hay que tomarlos en su justa consideración. No obstante, podemos señalar que estas características evidencian ciertas carencias sanitarias y de higiene que podrían ser indicativas de unas condiciones de vida humilde y de sobreesfuerzo físico propias de una población rural cuya economía se basa casi exclusivamente en el trabajo agropecuario.

\section{IV.3. LOS AJUARES}

Los elementos de ajuar recuperados han sido hallados en cuatro tumbas $(1474,1258,2238 \mathrm{a}$, y 2238c). Estos ajuares se componen de un elemento cerámico en cada una de ellas, y en algunos casos se acompañan de algún objeto metálico. Salvo una única excepción los ajuares están vinculados a las inhumaciones primarias. En general se trata de ajuares bastante pobres, que indicarían una catego- ría social poco destacable para los individuos con los que están asociados.

\section{IV.3.1. La cerámica}

Se han registrado un total de cuatro recipientes cerámicos depositados en cada una de las tumbas anteriormente mencionadas. El modelo básico es una jarrita en buen estado de conservación y completa, elaborada a torno mediante una cocción oxidante y con una representación variada en su morfología. Las piezas tienen una tonalidad de color que varía entre el beige y el ocre anaranjado, con unas superficies de aspecto cuidado que en ocasiones exhiben someros alisados.

Cabe destacar la variedad representativa en cuanto a las formas, con cuerpos piriformes (2238a y 2238c), bitroncocónico (1474) y fusiforme (1258), donde el tamaño varía entre los 15 y $20,5 \mathrm{~cm}$ de altura, no así el de la boca y la base, que son casi idénticos. En general tienen un asa de sección oval

\begin{tabular}{|c|c|c|c|c|c|c|}
\hline Estructura & Posición & Orientación & Sexo & Edad & $\begin{array}{c}\text { Medio de } \\
\text { descomposición }\end{array}$ & $\begin{array}{l}\text { Contexto } \\
\text { secundario }\end{array}$ \\
\hline 1475 & $\begin{array}{l}\text { decúbito } \\
\text { supino }\end{array}$ & $\begin{array}{c}\text { sagital a } 280^{\circ} \\
\text { Oeste }\end{array}$ & masculino & adulto & aerobio & \\
\hline 1474 & $\begin{array}{l}\text { decúbito } \\
\text { supino }\end{array}$ & $\begin{array}{c}\text { sagital a } 280^{\circ} \\
\text { Oeste }\end{array}$ & masculino & adulto & aerobio & masculino \\
\hline 1258 & $\begin{array}{l}\text { decúbito } \\
\text { supino }\end{array}$ & $\begin{array}{c}\text { sagital a } 275^{\circ} \\
\text { Oeste }\end{array}$ & masculino & adulto maduro & aerobio & femenino \\
\hline 2246 & $\begin{array}{l}\text { decúbito } \\
\text { supino }\end{array}$ & $\begin{array}{c}\text { sagital a } 240^{\circ} \\
\text { Oeste }\end{array}$ & $n / d$ & infantil & aerobio & \\
\hline 1257 & $\begin{array}{l}\text { decúbito } \\
\text { supino }\end{array}$ & $\begin{array}{c}\text { sagital a } 285^{\circ} \\
\text { Oeste }\end{array}$ & $n / d$ & infantil & aerobio & \\
\hline 1259 & & & masculino & adulto & & $\begin{array}{l}\text { restos } \\
\text { aislados }\end{array}$ \\
\hline 2238 UC-1 & $\begin{array}{l}\text { decúbito } \\
\text { supino }\end{array}$ & $\begin{array}{c}\text { sagital a } 285^{\circ} \\
\text { Oeste }\end{array}$ & masculino & adulto maduro & aerobio & masculino \\
\hline 2238 UC-2 & $\begin{array}{l}\text { decúbito } \\
\text { supino }\end{array}$ & $\begin{array}{c}\text { sagital a } 300^{\circ} \\
\text { Oeste }\end{array}$ & $n / d$ & infantil & aerobio & \\
\hline 2238 UC-3 & & & $\mathrm{n} / \mathrm{d}$ & & & $\mathrm{n} / \mathrm{d}$ \\
\hline
\end{tabular}

Figura 11. Cuadro resumen de los contextos funerarios. 
que arranca desde el borde y descansa en la zona media del cuerpo, excepto la pieza perteneciente a la estructura 2238 a, que presenta doble asa. Las bocas son circulares más o menos simétricas, salvo la jarrita de la tumba 2238c, de boca trilobulada.

Respecto al modelo que sigue la jarrita localizada en la estructura 1258, éste se integraría en la forma 1 de la clasificación de la cerámica de la necrópolis de Gerena (Sevilla) (Fernández, Sierra y Laso, 1987, 193). Se identifica además con la forma 16C, de cuerpo fusiforme y labio moldurado, de la sistematización de la cerámica funeraria de época visigoda realizada por R. Izquierdo (Izquierdo, 1977, 855), siendo un tipo bastante extendido por la región andaluza y extremeña (Gerena, Pedrera, San Pedro de Alcántara, El Campillo, Casa Herrera).

Su cronología se encuadra entre finales del siglo VI y el siglo VII (Flörchinger, 1998, 11, cuadro cronológico: tipo 4A).

Los paralelos tipológicos hallados para la jarrita de la tumba 1474 no son del todo exactos y claros, aunque es posible señalar rasgos muy similares a los que ésta ostenta, sobre todo en relación con la molduración o pequeña carena que presenta en el cuerpo, en recipientes hallados en las tumbas 14 , 15 y 25 de la necrópolis de la basílica de Gerena en Sevilla, agrupados en su forma 4 (Fernández, Sierra y Laso, 1987, figs. 36, 38 y 57).

El tipo representado por la jarrita de la estructura 2238a muestra estrechas conexiones tipológicas con modelos cerámicos tardorromanos, pudiéndose identificar con la forma $12 \mathrm{~A}$ de R. Izquierdo (Izquierdo, 1977, 850-851), la forma 6 de las piezas de la necrópolis hispano-visigoda en las Eras de Peñarrubia (Málaga) (Serrano y Alijo, 1989, 112) y el tipo 6.1 de la cerámica de la necrópolis de Gerena (Sevilla) (Fernández, Sierra y Laso, 1987, 194). Es un recipiente frecuente en necrópolis andaluzas (Gerena, San Pedro de Alcántara, Peñarrubia, Alcalá de los Gazules, El Tesorillo, y El Campillo) y extremeñas (Casa Herrera) y su cronología se encuadra entre finales del siglo VI y el siglo VII. Un ejemplar similar fue hallado en los años 70 del pasado siglo en la finca denominada "Nuestra Señora del Rocío", localizada en terrenos que son continuidad del yacimiento de La Orden-Seminario (Amo, 1976, fig. 48).

La forma del recipiente encontrado en la estructura 2238 c responde al tipo $15 \mathrm{~A}$ de la sistematización de la cerámica funeraria de época visigoda realizada por R. Izquierdo (Izquierdo, 1977, 854). También encontramos paralelos para este tipo de jarrita entre las piezas funerarias de El Gatillo (Cáceres) (Caballero, 1991, fig.1, 42). Se trata de piezas asimilables al grupo B de Santa Lucía del Trampal (Cáceres) de clara cronología visigoda (Caballero, Retuerce y Sáez, 2003, fig. 4, 22).

Se incluye en un grupo cerámico muy frecuente y heterogéneo, y su empleo está extendido por casi toda la Península Ibérica, particularmente en aquellas regiones donde el dominio romano fue muy intenso. Su cronología se sitúa durante la segunda mitad del siglo VI (Flörchinger, 1998, 14, cuadro cronológico: tipo 9B). Para algunos autores, estas jarras señalan una evolución dentro de una tipología enraizada con elementos indígenas y romanos y no con lo auténticamente visigodo (Lucas, 1971).

La documentación de elementos cerámicos hallados en las tumbas tiene un claro uso y funcionalidad ritual de carácter funerario, cuya práctica remonta su origen al mundo romano y mediterráneo, interpretándose como ofrendas para el difunto (Carmona, 1998, 103). Sin embargo, en la Antigüedad tardía estos elementos de ajuar adquieren un significado diferente que refuerza el carácter cristiano del difunto, interpretándose como un símbolo bautismal (Carmona, 1998, 103), aspecto que estaría en consonancia con la disposición de las piezas, que si bien existen excepciones, están depositadas generalmente en la cabecera de la sepultura.

Las jarritas de las tumbas 1258 y 1474 se disponen a la derecha del cráneo, cuya disposición sugiere claramente esta simbología ritual. También en la estructura 2238c la jarrita que compone su ajuar aparece colocada en el ángulo Suroeste de la tumba, aunque como se ha expuesto anteriormente, no se ha documentado una asociación directa con una posible inhumación primaria.

En cuanto a la tumba 2238a, como ya hemos indicado, el recipiente se hallaba colocado sobre el fémur izquierdo del individuo. Según un estudio elaborado por M. Cerrillo (1989) sobre las necrópolis de Extremadura y de la Meseta, se podría establecer una diferenciación en cuanto a la adscripción étnica o cultural del individuo atendiendo a la colocación en la fosa de este elemento de ajuar: la jarrita situada en la cabecera reconoce patrones hispanorromanos, y las colocadas entre la cintura y los pies corresponden a modelos genuinamente visigodos (Cerrillo, 1989, 104-106). No obstante, hay que tener en cuenta en este caso concreto la 
posibilidad de que su disposición pudiera deberse a una alteración de su posición original por procesos post-deposicionales. No es extraño, además, observar una gran variabilidad en cuanto a la posición de estos elementos dentro de las fosas, constatándose multitud de variaciones (cabecera, cadera, pies) en necrópolis como la de El Ruedo (Carmona, 1998, 103).

Atendiendo al significado simbólico y sociológico que adquiere en el ámbito de la magia y religiosidad romanas los conceptos espaciales de derecha e izquierda (Marco, 1986), se ha apuntado asimismo que la disposición de los recipientes cerámicos a un lado u otro de la cabecera podría relacionarse con el sexo del individuo inhumado, de manera que la jarrita colocada a la derecha del cráneo se relacionaría con los individuos varones, y las situadas a la izquierda, con los cadáveres de mujeres (Carmona, 1998, 178). Si bien esta correspondencia no se ve refrendada por los registros de la necrópolis de Casa Herrera (Mérida), en la que se ha obtenido una amplia información respecto a la estructura sexo/edad de las inhumaciones (Cerrillo, 1989, 106), en lo que respecta a la documentación de La Orden-Seminario, comprobamos la coincidencia con esta asociación en las tumbas 1258 y 1474, donde los ajuares tipo recipientes se disponen a la derecha del cráneo de los individuos masculinos enterrados en ellas.

\section{IV.3.2. Los objetos metálicos}

De las cuatro estructuras que contienen ajuar funerario, dos de ellas (1258 y 1474) han proporcionado objetos de metal además del elemento cerámico.

En la estructura 1474 se recuperó un anillo de cinta de bronce en el relleno que cubre los restos de un osario que se encontraba depositado sobre la cubierta de la tumba. Es muy probable que este objeto estuviese asociado al individuo cuyos restos cubre este relleno, pero no tenemos la certeza de si ese mismo individuo se correspondería con la primera inhumación de la sepultura, la cual sería posteriormente retirada para alojar el nuevo cadáver en un reaprovechamiento de la misma.

Por su parte, el ajuar de la estructura 1258 se compone de tres objetos de hierro: una herramienta que relacionamos con el curtido de la piel, una pequeña hebilla de cinturón y un broche de cinturón de placa rígida sencilla de forma liriforme.

Siguiendo la tradición romana, el uso de anillos tuvo un gran desarrollo en época visigoda y su empleo tan extendido está relacionado con la difusión del Cristianismo, apareciendo en numerosas ocasiones asociados a símbolos y advocaciones religiosas de este signo (López y Barroso, 1994, 53).

El tipo de anillo de cinta con el frente ensanchado y decoración incisa hallado en la estructura 1474 se corresponde con el tipo II de los estudiados por Almagro Basch para la necrópolis de Segóbriga (Almagro, 1975, 114-115), siendo un objeto muy común en los ajuares de necrópolis conquenses como Almodóvar del Pinar (Almagro, 1970, fig. 5, 1-3), La Dehesa de la Casa y Villar de la Encina (López y Barroso, 1994, 55, lám. 46 y 47), entre otras.

Su cronología se encuadra en el período de transición entre los siglos VI-VII, fecha muy acorde con la cronología constatada para otros elementos de ajuar de esta misma tumba como es la jarrita. Se trata de un momento en el que, en lo que se refiere a los elementos de adorno personal, se produce un cambio de gusto estético derivado de la influencia del mundo oriental bizantino (López y Barroso, 1994, 63-65), un hecho que se relaciona satisfactoriamente con otro elemento de ajuar como es el broche de cinturón hallado en la estructura 1258 que estudiaremos a continuación.

El broche de cinturón de la tumba 1258, de placa rígida sencilla de forma liriforme, responde a un modelo que empieza a ser frecuente en la Bética y particularmente en la región sevillana a partir de finales del siglo VI; se encuentran igualmente paralelos para estos broches en la necrópolis de El Tesorillo en Málaga (Ripoll, 1998, 106-108).

Tipológicamente, estas piezas están a medio camino entre los broches de cinturón de placa rígida simple y los liriformes, por lo que son llamados de transición. Su cronología se sitúa en el tránsito entre los siglos VI-VII, nuevamente en ese período de paso de una "toréutica realizada por artesanos visigodos con viejas influencias germánicas, a una toréutica de clara influencia y carácter bizantinomediterráneo llegada a la península en los últimos momentos del siglo VI a través del comercio con el mediterráneo y las colonias costeras" (Ripoll, 1998, 109).

El elevado número de hallazgos procedentes de la región hispalense sugiere la existencia de un taller ubicado en esta zona que trabajó durante este período (Ripoll, 1998, 111).

Como podemos comprobar, se constata una clara relación, no sólo cronológica sino también en cuanto a esta influencia oriental, en las modas que atañen a los elementos de adorno personal (anillo, 
broche). Además, como ya se ha indicado con anterioridad, hay que señalar que las cronologías que se manejan para estos objetos concuerdan perfectamente con las de otros elementos de ajuar como las jarritas halladas en las tumbas.

En esta misma estructura se ha registrado también una hebilla de cinturón de forma ochavada para la que desafortunadamente no se han encontrado paralelos ni similitudes tipológicas exactas. No obstante por su morfología simple podemos aventurar que su uso estaría muy extendido cronológicamente.

Por último, entre los objetos de metal que componen el ajuar de la tumba 1258, se recuperó una herramienta para el curtido de pieles, que encuentra paralelos en enterramientos de la Cueva de Los Goros (Álava), donde aparece junto a materiales que fechan el conjunto en la segunda mitad del siglo VII (Ripoll, 1991, 665-666), así como también en el enterramiento número 4 de la necrópolis hispanovisigoda de Palous (Camarasa, Lleida), donde se encuentra acompañada de un broche de cinturón de tipo liriforme (Solanes y Alós, 2003, fig. 4). En este último yacimiento los materiales de ajuar fechan la estructura entre la segunda mitad del siglo VII e inicios del siglo VIII.

\section{CONSIDERACIONES FINALES Y CONCLUSIONES}

La información con que contamos para el estudio de la Antigüedad tardía y la época visigoda en la provincia de Huelva es a todas luces escasa e insuficiente actualmente, tanto por la parquedad de las fuentes textuales y lo limitado del registro arqueológico, como por la falta de estudios generales y de síntesis. No obstante, en lo que se refiere al estudio de las manifestaciones funerarias tardoantiguas, gracias a la labor arqueológica de los últimos años se ha visto incrementado notablemente el número de hallazgos significativos y, consecuentemente, el nivel de conocimiento de este periodo histórico en la zona más occidental de la Bética.

En este sentido, en el ámbito de la Tierra Llana de Huelva es de destacar los trabajos realizados por parte del Área de Arqueología de la Universidad de Huelva en el yacimiento de El Eucaliptal (Punta Umbría), donde se han documentado restos del poblado romano, instalaciones industriales y un área de necrópolis, en cuya Fase III, representada por inhumaciones orientadas a Poniente en tumbas de ladrillos, parece haberse adoptado definitivamente, ya a inicios del siglo $\mathrm{V}$, el rito cristiano (Campos, Pérez y
Vidal, 1999, 96; Campos, Pérez y Vidal, 1999, 229).

Por otra parte, en el año 2004 se realizaron excavaciones en la finca "Las Reliquias" (Cartaya) (López et al., 2009), donde se documentaron cuarenta y nueve enterramientos pertenecientes a una necrópolis rural tardorromana/visigoda, cuya cronología abarca desde el siglo IV al VII. Se trata de la segunda mayor necrópolis excavada en la provincia por su número de enterramientos tras la de El Eucaliptal en Punta Umbría.

En Los Bojeos de Bonares se delimitó una extensa área de asentamiento rural de época romana, donde además se descubrió, entre otros hallazgos, la lápida funeraria del obispo Vincomalos, uno de los documentos más importantes de la provincia de Huelva para el período visigodo (Pérez, González y Oepen, 2004).

También en la zona del Condado de Huelva se encuentra la necrópolis de El Lomo (Bollullos par del Condado), con tan solo dos tumbas excavadas que se fechan entre los siglos V y VII (García, 1997).

En la comarca de la Sierra se localiza la necrópolis de Santo Ángel (Almonaster la Real) fechada en el siglo IV (Pérez y Gómez, 1989). De este sector de la provincia proceden dos jarritas de época tardoantigua, una del casco urbano de Higuera de la Sierra y otra del paraje de "Tejonera" en el término municipal de Cortegana, encuadrables entre los siglos VI y VII (López, 2000). En Aroche se han documentado jarritos tardorromanos-visigodos en Los Benitos y Las Peñas (Pérez, 1987).

Por último, en la Cuenca Minera, debemos mencionar la necrópolis de El Cerro de la Cebada (El Campillo), que se fecharía a principios del siglo V (Fuentes y Gómez, 1988).

Centrándonos en la ciudad de Huelva, el hallazgo de la necrópolis tardoantigua del yacimiento de La Orden-Seminario reviste cierta importancia para la investigación de las manifestaciones funerarias de este período histórico, ya que se trata de uno de los pocos testimonios de esta naturaleza registrados en la ciudad, junto con la cercana necrópolis de La Orden excavada en los años 70 por M. del Amo (1976). En esta última zona se localizaron un total de cuarenta enterramientos con el único rito funerario de la inhumación, habiéndose registrado reutilizaciones sucesivas en dos de las tumbas (sepulturas $\mathrm{n}^{\mathrm{o}} 15$ y 21). En la tumba 21 se constató la presencia de ajuar consistente en un pequeño jarro de "tipo visigodo" (Amo, 1976, fig. 45). La cronología de uso de la necrópolis abarcaría según su ex- 
cavador desde principios del siglo IV hasta buena parte del siglo V (Amo, 1976, 98-109).

Por estas mismas fechas se produce el hallazgo fortuito de una tumba tardorromana en la finca de Nuestra Señora del Rocío, localizada muy cerca del cementerio actual de Huelva y junto a la Ronda exterior Norte. La sepultura contenía también, como elemento de ajuar, un pequeño jarro de "tipo visigodo" y alojaba los restos de tres individuos. A juzgar por los hallazgos localizados en las tierras removidas por la maquinaria, la tumba "...hubo de formar parte de una necrópolis”, cuya cronología la sitúa M. del Amo en un momento no anterior al siglo V (Amo, 1976, 110-112)

Al igual que estas dos localizaciones, muy próximas entre sí, la necrópolis tardoantigua de La Orden-Seminario se ubica, a nivel macroespacial, en el ruedo agrícola de la Onoba romana, y seguramente esté relacionada con asentamientos rurales dedicados a la explotación agrícola del territorio (villae). Por otra parte, el hallazgo de ánforas de salazón de época tardía en La Orden es indicativo de una actividad pesquera y de producción de salazones (O’Kelly, 2012), por lo que habría que suponer que algunos de estos asentamientos periurbanos podrían ser del tipo cetariae.

La concentración de restos arqueológicos y su proliferación en la zona de la Orden y de la barriada contigua de El Torrejón, conocidos ya de antiguo (Carriazo, 2006), aparte de su vinculación con la explotación de la tierra y de su función de abastecimiento a la ciudad, vendría determinada asimismo por el trazado de la vía romana que por esta zona salía desde Onoba y se dirigía hasta la actual población de San Juan del Puerto (Pérez Quintero, 1794, 78). En este sentido, cabe señalar que la necrópolis de La Orden-Seminario se localiza en la margen oriental del camino histórico principal de acceso Norte a la ciudad, relacionable con el trazado de esta calzada que sigue el camino del actual cementerio de Huelva hasta cruzar la ribera de la Anicoba.

Aunque, como ya hemos señalado, contamos con documentación sobre necrópolis tardías en la provincia y en la capital, el área cementerial de La Orden-Seminario se convierte por ahora, gracias a su estado de conservación y al espectro cronológico que abarca, en paradigma de necrópolis hispano-visigoda en la ciudad de Huelva y supone la continuidad de los contextos socioeconómicos tardorromanos representados principalmente por la necrópolis de La Orden hasta bien entrado el siglo VII.
El modelo territorial que refleja la realidad arqueológica para esta época parece vincularse a un régimen de propiedad rústica materializado en pequeños núcleos de población (villa, fundus, vicus), a los que, con carácter general, aparecen relacionadas las necrópolis, aunque no siempre es posible documentar dicha asociación (Carmona, 1998). Es este el caso de La Orden-Seminario donde no existe constancia arqueológica del asentamiento al que la necrópolis estaría vinculada. De todos modos, las zanjas de cultivo y silos romanos (del tipo denominado puteus por los agrónomos latinos) documentados en La Orden-Seminario, algunos localizados en zonas muy próximas al espacio funerario, hablan de una explotación continuada y efectiva del territorio y, si bien el sector más noroccidental del yacimiento aún no ha sido intervenido, estas evidencias parecen indicar que el antiguo cortijo de Nuestra Señora del Rocío, aún en pie hasta hace escasamente una década, constituya la continuidad de un establecimiento rural al menos desde la época bajoimperial romana.

Un modelo similar se atestigua en el yacimiento de El Cabezo de La Almagra (Vidal et al., 2013), situado en el Campus Universitario de El Carmen, que desarrolla una ocupación diacrónica iniciada en época romana y que se mantiene hasta época contemporánea. Reproduce un modelo de poblamiento rural que es característico de la Tierra Llana, basado en un asentamiento del tipo villa rustica romana que continúa funcionando en época medieval como alquería islámica y por último como cortijo moderno-contemporáneo. Dispondría igualmente de un área funeraria de la que se ha documentado únicamente un enterramiento perteneciente a la fase ocupacional de época medieval.

Otros vestigios en el entorno inmediato al yacimiento de La Orden-Seminario que avalan esta propuesta son el hallazgo de un posible asentamiento rural de época bajoimperial en Peguerillas II, y los sitios de La Soledad y El Ventolín, próximos al cementerio, caracterizados por una gran abundancia de material constructivo y cerámico y por estar situados todos en el ager de la ciudad romana (Campos, 2009, 149).

En la necrópolis tardoantigua de La Orden-Seminario se han documentado siete enterramientos primarios y otros seis en contexto secundario cuyo único rito funerario es la inhumación, con los cadáveres en posición de decúbito supino, y en los que en cuatro casos se han encontrado elementos de 
ajuar. Las sepulturas presentan cubiertas confeccionadas con lajas de pizarra, fragmentos de ladrillo y en ocasiones con sillares de piedra. Algunas de las tumbas han sido reutilizadas y contienen restos secundarios en forma de osarios. No se ha constatado una delimitación del espacio funerario, una característica común de las necrópolis del período tardorromano en Andalucía, en las que, hasta el momento, tampoco se ha registrado ningún tipo de cerca o delimitación de las áreas de cementerio (Carmona, 1998). Los elementos de ajuar, junto a las características morfológicas de las sepulturas y los datos comparativos extraídos de las publicaciones de otras necrópolis que hemos manejado, nos han permitido establecer una cronología para esta necrópolis que abarca la segunda mitad del siglo VI y el siglo VII.

El ritual funerario documentado constata la pervivencia de tradiciones tardorromanas en las poblaciones rurales del entorno agrícola de la ciudad de Onoba y su posible adscripción étnica con el sustrato poblacional hispanorromano. De hecho, las necrópolis rurales tardoantiguas y de época visigoda documentadas en el marco geográfico de Andalucía se asimilan en su gran mayoría a un hábitat $\mathrm{y}$ a un sustrato poblacional hispanorromano que pervive hasta bien avanzado el siglo VII (Carmona, 1998). Tanto por el análisis de la cultura material como por el estudio antropológico, podemos decir que en la necrópolis de La Orden-Seminario no se constatan elementos puramente visigóticos en el sentido étnico del término.

El estudio antropológico de los restos óseos, y en concreto la determinación de diversas patologías, demuestra que nos encontramos ante una población cuya actividad ocupacional implicaría un gran esfuerzo físico, hecho que podría ponerse en relación con la agricultura como principal actividad económica. De otra parte, el descarnador/ curtidor de la tumba 1258 y su relación con los rasgos patológicos del individuo inhumado, pone en evidencia la existencia de otras actividades económicas apoyadas en la ganadería, que vendría a ser en este contexto una actividad complementaria de la agricultura, al tiempo que certifica la importancia del trabajo artesanal para estas poblaciones y la existencia de individuos especializados en determinadas manufacturas. Respecto a la tumba 1258 , la concentración de ciertos elementos de ajuar y la calidad en la construcción de la misma, podría interpretarse como indicadores de una cierta dife- renciación social, que estaría avalada quizás por la consideración del individuo como artesano en un contexto social donde la mayoría de la población se ocuparía de las tareas agrícolas. En todo caso, las condiciones de vida debieron de ser precarias y duras para estas poblaciones rurales y en este sentido se manifiestan los datos de mortalidad infantil y las patologías registrados.

Cabe destacar por último que las variaciones no métricas estudiadas en los esqueletos de los dos individuos depositados en la tumba 1258 permiten el reconocimiento de relaciones genéticas entre ambos, lo que posibilita su posible adscripción a un mismo grupo de parentesco que amortizaría la sepultura en dos fases sucesivas. Aunque no poseemos información osteológica que avale esta interpretación en las reutilizaciones de los enterramientos 1474 y 2238a, en el caso de este último con las circunstancias que ya hemos reseñado, el dato sobre la reutilización de las tumbas por miembros de un mismo grupo familiar que aporta la estructura 1258 podría ser extrapolado a estas otras, una interpretación que por otra parte abunda en los estudios sobre necrópolis hispano-visigodas.

En resumen, la necrópolis tardoantigua de La Orden-Seminario funcionaría como una pequeña área funeraria asociada a un asentamiento rural del tipo villa, similar a la localizada en el Cabezo de La Almagra (Vidal et al., 2013), y estaría ubicada, como se constata en otras necrópolis de este mismo período, próxima a una de las vías principales de comunicación del territorio, en este caso, la antigua vía romana de acceso Norte de la ciudad de Huelva. La necrópolis, así como otros vestigios existentes en la zona de La Orden y El Torrejón, constatan la existencia de una explotación continuada y efectiva del territorio periurbano de la ciudad de Huelva desde época romana, con una población dedicada básicamente a la agricultura, cuyos excedentes en la producción podrían abastecer al núcleo urbano.

\section{Bibliografía}

Almagro Basch, M. (1975), La necrópolis hispano-visigoda de Segóbriga, Saelices (Cuenca), Excavaciones Arqueológicas en España, 84, Madrid.

Almagro Gorbea, M. (1970), "Hallazgos de época visigoda en Almodóvar del Pinar", Trabajos de Prehistoria, 27 (1), 311-323.

Amo y de la Hera, M. del (1976), Restos materia- 
les de la población romana de Onuba, Huelva Arqueológica, 2, Huelva.

Caballero Zoreda, I. (1991), "La iglesia de época paleocristiana y visigoda de El Gatillo de Arriba (Cáceres)". Extremadura Arqueológica, II, 471-497.

Caballero Zoreda, L., Retuerce Velasco, M. y Sáez Lara, F. (2003), "Las cerámicas del primer momento de Santa María de Melque (Toledo), construcción, uso y destrucción. Comparación con las de Santa Lucía del Trampal y El Gatillo (Cáceres)", Cerámicas tardorromanas y altomedievales en la Península Ibérica. Ruptura y continuidad (Caballero, L., Mateos, P. y Retuerce, M., Eds.), II Simposio de Arqueología. Mérida, 2001, Anejos de Archivo Español de Arqueología, XXVIII, Madrid, 225-271.

Campos, J. M., Pérez, J. A, y Vidal, N. (1999), Las cetariae del litoral onubense en época romana, Huelva.

Campos Carrasco, J. M. (2009), Onoba Aestuaria. Una ciudad portuaria en los confines de la Baetica, Huelva.

Campos, J. M., Pérez, J. A. y Vidal, N. (1999), “El eucaliptal, una necrópolis romana de pescadores (Punta Umbría, Huelva)", Huelva en su Historia, 7, 195-231.

Carmona Berenguer, S. (1998), Mundo funerario rural en la Andalucía tardoantigua y de época visigoda. La necrópolis tardorromana de El Ruedo, (Almedinila, Córdoba), Córdoba.

Carriazo Rubio, J.L. (2006), "Noticia decimonónica sobre una necrópolis romana y un tesorillo islámico en el Torrejón (Huelva)", Aestuaria: revista de investigación, 9, 207-216.

Cerrillo Martín de Cáceres, E. (1989), "El mundo funerario y religioso de época visigoda”, III Congreso de Arqueología Medieval Española, I, Oviedo, 89-110.

Fernández Gómez, F., Sierra Fernández, J.A. de la, y Lasso de la Vega, Mª.G. (1987), "La basílica y necrópolis paleocristianas de Gerena (Sevilla)", Noticiario Arqueológico Hispánico, 29, 103199.

Flörchinger, A. (1998), Romanische Gräber in Südspanien: beigaben-und Bestattungssitte in westgotenzeitlichen Kirchennekropolen, Rahden/Westf.: Leidorf.

Fuentes Domínguez, A. y Gómez Ruíz, A. (1988), "El yacimiento romano de El Cerro de la Cebada, El Campillo (Huelva)", I Congreso Na- cional Cuenca Minera de Riotinto. Memoria, Nerva, 111-140.

García González, F. M. (1997), "Intervención arqueológica de urgencia en la necrópolis de El Lomo, Bollullos par del Condado (Huelva)", Anuario Arqueológico de Andalucía /1993, III, 290-296.

González González, B., Linares Catela, J. A., Vera Rodríguez, J. C., y González Batanero, D. (2008), "Depotfund Zylinderförmiger Idole des 3 jts. v. chr. aus La Orden-Seminario (prov. Huelva)", Madrider Mitteilungen 49,1-28.

Izquierdo Benito, R. (1977), "Ensayo de una sistematización tipológica de la cerámica de necrópolis de época visigoda", Revista de archivos, bibliotecas y museos, LXXX, 4, 837-865.

Lacort Navarro, P. J. y Del Pino García, J. L. (1995), "Necrópolis tardorromana-visigótica de Reynilla (Guadalcázar, Córdoba). Intervención arqueológica de urgencia, enero 1994", Ariad$n a, 15,49-62$.

López Domínguez, M. A. (2000), "Sobre dos jarros a mano de época visigoda de la sierra de Huelva”, XIV Jornadas de Patrimonio de la Sierra de Huelva, Huelva, 357-367.

López Domínguez, M. A., Castilla Reyes, E., De Haro Ordóñez, J., y Quintero Cristóbal, M. C. (2009), "Intervención Arqueológica de Urgencia en la finca las Reliquias (Cartaya, Huelva)", Anuario Arqueológico de Andalucía /2004. 1, 1696-1708.

López Flores, I. (2006),Informe Antropológico de los restos procedentes de la Intervención Arqueológica Sector 8 (Seminario) de Huelva 2005, Inédito.

López Flores, I. (2009), Base de datos antropológica PP8 "Seminario" Huelva, Inédito.

López Quiroga, J. (2010), Arqueología del mundo funerario en la Península Ibérica (siglos $V$-X), Madrid.

López Requena, M. y Barroso Cabrera, R. (1994), La necrópolis de la Dehesa de la Casa. Una aproximación al estudio de la época visigoda en la provincia de Cuenca, Cuenca.

Lucas de Viñas, Mª . R. (1971), "Necrópolis de El Cantosal, Coca (Segovia)”, Noticiario Arqueológico Hispánico, 16, 381-396.

Marco Simón, F. (1986), “Topografía cualitativa en la magia romana: izquierda y derecha como elementos de determinación simbólica”, Memorias de Historia Antigua, VII, 81-90. 
Morín de Pablos, J. y Barroso Cabrera, R. (2005), "El mundo funerario de época visigoda en la Comunidad de Madrid. El poblamiento y el problema del asentamiento de los visigodos en la Península Ibérica a través del estudio de las necrópolis madrileñas", Actas de las Primeras Jornadas de Patrimonio Arqueológico en la Comunidad de Madrid, 183-213.

O'kelly Sendrós, J. (2012), "Ánforas onubenses de época tardorromana", Cerámicas hispanorromanas, II. Producciones regionales, Cádiz, 279-295.

Pérez Macías, J. A. (1987), Carta Arqueológica de los Picos de Aroche, Huelva.

Pérez Macías, J. A. y Gómez Multo, S. (1989), “La necrópolis de Santo Ángel (Almonaster la Real, Huelva) y el mundo tardorromano en la Sierra de Huelva", IV Jornadas de Patrimonio de la Sierra de Huelva. Huelva, 189-193.

Pérez, J. A., González, J. y Oepen, A. (2004), Los Bojeos de Bonares (Huelva) y el obispado visigodo de Niebla, Huelva.

Pérez Quintero, M.I. (1794), La Beturia vindica$d a$, edición facsímil en: Lara Ródenas, M.J.: Un heterodoxo en la Huelva de la Ilustración: Miguel Ignacio Pérez Quintero, reimpresión Huelva 1995.

Ripoll López, G. (1991), La ocupación visigoda en época romana a través de sus necrópolis (Hispania), Collecció de Tesis Microfitxades $\mathrm{n}^{\mathrm{Q}}$ 912, Barcelona, Servei de Publicacions de la Universitat de Barcelona.

Ripoll López, G. (1998), Toréutica de la Bética. Siglos VI y VII d.C, Barcelona.

Serrano Ramos, E. y Alijo Hidalgo, F. (1989), "Una necrópolis hispano-visigoda en las Eras de Peñarrubia (Málaga),III Congreso de Arqueología Medieval Española, I, Oviedo,110-121.

Solanes Potrony, E. y Alós Trepat, C. (2003), "Interpretació de l'aixovar de la necrópolis hispanovisigoda de Palous (Camarasa, la Noguera): apunts sobre l'adobat de pells a l'antiguitat tardana", Revista d'Arqueologia de Ponent, 13, 345-350.

Toro Moyano, I. y Ramos Linaza, M. (1987), “Excavación de urgencia en la necrópolis visigoda de las Delicias (Ventas de Zafarraya, Alhama de Granada) 1985", Anuario Arqueológico de Andalucía / 1985. III, 143-149.

Vera, J.C., Linares, J. A., Armenteros, $\mathrm{M}^{\mathrm{a}}$ J. y
González, D. (2010), “Depósitos de ídolos en el poblado de La Orden-Seminario de Huelva: Espacios rituales en contexto habitacional", Ojos que nunca se cierran. Ídolos en las primeras sociedades campesinas, Madrid, 199-242

Vidal, N., Campos, J. M., Gómez, A., y Sánchez, L. (2013), "El mundo rural en el entorno de Huelva desde la Antigüedad hasta el mundo contemporáneo: el cabezo de la Almagra”, Arqueología en la provincia de Huelva: homenaje a Francisco Javier Rastrojo Lunar, Huelva, 176-205.

Young, B. K. (1977), Paganismo, Christianisation et rites funéraries merovingies”, Archéologie Medieval, VII, 5-81. 